\title{
Modeling Covid-19 Pandemic Responses in Malaysia for the First 145 Days Duration (Jan. 25 - June 17, 2020)
}

Danial Kafi Ahmad ( $\boldsymbol{\nabla}$ danialkafi.ahmad@newinti.edu.my)

INTI International University and Colleges

Ahmad Selamat

Other Press

Mohd Nazmi Ahmad

Universiti Tenaga Nasional

Abdullah Syafiq Ahmad

Other Press

\section{Research}

Keywords: Covid-19, Malaysia, 145 days, World Health Organization (WHO)

Posted Date: July 1 st, 2020

DOI: https://doi.org/10.21203/rs.3.rs-39218/v1

License: (a) (i) This work is licensed under a Creative Commons Attribution 4.0 International License. Read Full License 


\section{Modeling Covid-19 pandemic responses in Malaysia for the first 145 days duration}

(Jan. 25-June 17, 2020)

A Selamat, D.K. Ahmad, M.N. Ahmad, and A.S. Ahmad.

Corresponding author: D.K. Ahmad danialkafi.ahmad@newinti.edu.my

\section{Abstract}

\section{Background}

At 145 days from Jan. 25, the Covid-19 recovery rate was $92.5 \%$ of the total cumulative cases of 8,515 with 1.4\% fatalities were recorded in Malaysia. On top of the provided medical services and facilities, the recoveries could be mainly resulted from the Movement Control Order (MCO) enforcements in six phases for mitigating the pandemic nationwide. To understand the Covid-19 pandemic trend and dynamic mathematically to the MCO phases, the applicability of the proposed models ( tri-logistic growth model) on covid-19 related responses was studied by using the 'matured' 145 -day data duration. The study also aimed at, (1) identifying information/parameters obtained through modeling technique that could be used in explaining the pattern of dynamic subjected to MCO enforcements, and (2) forecasting the quantitative information for postdate days beyond the used data duration.

\section{Methods}

Each serial layered-logistic growth of cumulative cases, recoveries, fatalities, and active cases were linked among them via the asymptotic cumulative cases and the nature of the recovery-fatality complementarity. The used data of Jan. 25 - Jun. 17, 2020 were quite 'matured' trend as observed in the 'plateauing' of cumulative cases. The appropriate $\mathrm{R}^{2}$ was used for model fitness analysis. The innovative SAS program writing of SAS9.4 version was used for the analysis. 


\section{Conclusion}

Predicted cumulative cases, recoveries, fatalities, and active cases vs. days were significantly fitted to the observed values $\left(R^{2}>99 \%\right)$, indicating the validity of the tri-logistic growth proposed model. Via the derivative of cumulative cases function, the daily cases or dynamic model was significant $\left(R^{2}=70 \%\right)$ with the fluctuating daily cases moved around the predicted curve. The authority has been classified the pandemic as of two waves (Jan. 25 - Feb. 26, 2020, and Feb. 27, 2020 onwards), and these were regrouped as wave 1 (primary wave) in this study. Within this one wave, the study shows that covid-19 in Malaysia has three cycles: cycle 1(1º cycle) [Jan. 25 - Apr.27], cycle 2 [Apr. 28 - May 14] and cycle 3 [May 15 and onwards] with the aggressiveness order of wave 1 > wave 3 > wave 2 (wave 3 had mainly caused by local foreigners). The observed cumulative cases were slightly higher than the predicted (by $0.07 \%-0.49 \%)$ during Jun $13-17$ suggesting small room of resources still available for covid-19 infection, thus, maintaining the current MCO is crucial. Beyond Jun.17, the forecasts of cumulative cases, recoveries, fatalities, and active cases at June 30 would be 8500, 8168, 128, and 202 cases, respectively, with daily cases of 1 case day ${ }^{-1}$. If no any further odd-extraordinary wave occurrence, the country would probably be enjoying a non-significant covid or 'covid-free' pandemic by the July end or mid-August, 2020. The model had validated the correctness and appropriateness of the MCO phases' enforcements. The active cases model was the resultant of linkages of all models via asymptotic cumulative cases. Based on above resultant and the logistic growth function applicability in various fields, the modeling approach involving serial tri-logistic functions could probably be used in analyzing covid or covid-related epidemic elsewhere and in the future. 


\section{Introduction}

As of June 17, 2020, the total global covid-19 cases were 8,295,151 cases with recovery and fatality rates of 52.4 and $5.4 \%$, respectively [1]. The World Health Organization (WHO) had characterized covid-19 as pandemic on March 11,2020[2], and as of June 17, 2020, the pandemic has been affecting of more than 200 countries worldwide [1]. With the initial name of $2109-n C o V$, the virus is a positive, enveloped, and single-strand RNA [3]. It has many similarities with the MERS-CoV (Middle East Respiratory Syndrome) and SARS-CoV (Severe Acute Respiratory Syndrome). The first suspected case in Wuhan, China was on December 8, 2019 [3]. Wuhan of Hubei is the epicenter of the outbreak of 2019-nCoV or 2019 Novel Coronavirus, and specifically the disease is called Covid19. It was reported on Jan25, 2020 ( date coincided with the first covid-19 wave in Malaysia) that the epidemic had caused at least 41 fatalities, and the virus had spread to other countries, including Singapore, Japan, the US, France, and Australia [4].

In Malaysia, the first wave occurred during the period of Jan 24 - Feb. 26, 2020 with 22 cases including the daily zero case for the period of 11 days (Feb. $16-26,2020)$ [5]. In this wave, there were 12, 8, and 2 cases of those had a travel history to affected countries, close contacts, from a humanitarian mission, respectively, and by the end of wave 1 , all of them were fully recovered and discharged[ 6]. The second wave started from Feb., 27, 2020 [7]. The covid-19 cases that initially low ( first wave) in number and principally sourced from importation had aggressively increased due to the localized infection starting in the late February to early March that partly contributed by the Tabligh gathering in Sri Petaling Mosque with 14,500 participants. From this point, the cases had reached to the figure of more than 2,500 cases at the end of March. Additionally, by March 16, 2020, all states and Federal territories had recorded Covid-19 pandemic infection $[8,9]$. 
The above observed exponential and alarming increasing trend of covid-19 cases, and if it is not well and appropriately controlled and mitigated, the nation economy and wellbeing of the people would be negatively affected. Thus, the interventions in containing and mitigating the covid-19 spread are being made by the Malaysian government through the enforcement of the movement control order (MCO) starting from March 18, 2020. The MCO has been enforced in phases, i.e., MCO1 ( March 18 - 31, 2020), MCO2 ( April 1 - 14, 2020), MCO3( April 15 - 28, 2020), MCO4 ( April 29 - May 12, 2020), MCO5 ( May 13 - June 9,2020 : conditional MCO), and currently recovery MCO (RMCO: 10 June - August 31, 2020) [9]. In MCO1, there are orders of prohibiting mass gathering; requirements of undergoing health check and 14-day self-quarantine for Malaysians returning from abroad; restricting the entry of tourists and foreign visitors; closing all kindergartens, schools, and pre-university institutions; closure of higher education institution; and the closure of all government and private premises with the exception of those providing essential services to the public. All above are fundamentally enforcing social distancing and the practices of 'new normal' ways of life. The MCO extensions are being enforced due to significant increase of cases over time and the possibility of cases to peak at Mid-April as predicted by the WHO. In the CMCO and RMCO, due to convincing lower daily cases, some relaxations of orders for reopening the business, and allowing more movements and activities with new normal ways[ 9,10$]$, but these relaxations are still bound to the previous or updated standard operating procedures that principally and basically based on the social distancing and self-hygiene or personal-hygiene practices.

There must be a social and scientific basis, and professional opinion to be used in forming the form of intervention and relevant time duration or period in controlling and mitigating the pandemic. A part from qualitative tools, mathematical modeling could be used as guideline or tools in the planning and making decision related to any intervention to be made in mitigating certain disease epidemic for the benefit of the public health[11]. In epidemic or pandemic of disease that especially caused by viral infection, the 
cases would be normally trended with nonlinear pattern and chaotic in nature. These can be seen from the scientific reports and publications in the infection of covid-19[3], SARS [12], H1N1 [13], and Ebola [14]. The viruses need hosts to grow (or replicate) in a given conducive environment where the hosts would be ranging from humans, domestic animals, and to natural ecosystem [15]. As generally termed as microbial, the growth rate of the population size in the unlimited and limited resources would be proportional and a function of population size, respectively [16]. Thus, it is assumed that the enforcements of serial MCO phases in Malaysia would lead into environment of limiting resources for the spread of covid-19 virus. Thus, by taking the equivalent of Covid-19 virus population size to covid-19 infected persons, the cumulative cases over days model is basically represented by the growth logistic function. Several workers have used this function or other exponential related models in describing epidemic/pandemic of viral diseases including covid-19 virus $[3,17,18,19,20,21$, and 22]. The applicability of logistic function is generally used in a quite high number of modeling works. In neural network study that implemented in artificial neural networks (NAA) with artificial neurons, the logistic function is generally used as an activation function in the NAA [23].

As of June 17, 2020 (145 days after the first positive diagnosed covid on Jan. 24, 2020), the Malaysia's recoveries and fatalities were $92 \%$ and $1.4 \%$, respectively; and the respective global figures were $52 \%$ and $5.4 \%$ [1]. With the assumption of no additional significant new covid wave occurrence, the daily cases' curve would be seen as on the down-trend that observed within the enforced rehabilitation MCO phases towards reaching the covid-free or non-significant covid infestation condition. Thus, based on data of Jan. 25 - June 17(145 days), i.e., considering the pandemic has already been entering into the 'maturity stage', the study was firstly aimed at the applicability of the proposed serial layered-logistic growth function in determining mathematically the trends of covid-19 pandemic on cumulative cases, recoveries, fatalities, and active cases over days; and its related dynamic model. Secondly, the aim was to 
identify the information and parameter values that could be obtained or extracted through modeling technique in understanding the observed dynamic of the pandemic. With these identifications, specifically, the model would be used to determine that parameter value that linking all above models, and to determine the possibility of the occurrences of several cycles of wave during the study period. The information could also be used as guidelines for reallocation and remobilization of resources by the relevant authorities at postdate days of duration where the data were used for modeling. Thirdly, the aim was to forecast the quantitative information for days beyond the duration of data used in the study. In overall, the study was aimed at observing the correctness and appropriateness of the enforced MCO phases in the covid-19 mitigation by overlying the model trends on the MCO zonings or phases. It was noted that the zero daily cases in wave 1 were 11 days [5] as opposed to the covid-19 virus incubation period of 14 days [24] and the required zero daily cases for 28 days[25]. Additionally, the early phase of the cumulative cases trend in China [3] was quite resembling to that in Malaysia. Thus, it would be logical, this study had grouped waves 1 and 2 in Malaysia to be as one wave only.

\section{Methods}

\section{Microbial population growth.}

Theoretically, the rate of microbial population growth that hypothetically including viruses in certain culture/environment over time $\left(\frac{d n}{d t}\right)$ is proportional to and a function of population size under an unlimited and limited resources or environment, respectively [16]. The resultant function is shown in Eq. (1).

$$
\frac{d n}{d t}=k n\left(1-\frac{1}{\alpha} n\right)
$$

Where, $\mathrm{t}=$ time, $\mathrm{n}=$ number of microbial or colony size, 
$k$ and $n=$ constant and population size, respectively.

The $k n$ and $\left(1-\frac{1}{\alpha} n\right)$ represent the quantitative intrinsic property and the sum total of environmental restriction/limitation, respectively [16]. In this discussion, we would replace ' $n$ ' with ' $y$ ', i.e., it is a generally used for mathematical elaboration. If we define the microbial growth rate as $\frac{d y}{d t}$, then the relative growth rate $(\mathrm{R})$ can be written as shown in Eq. (2).

$$
\mathrm{R}=\frac{1}{y} \frac{d y}{d t}
$$

By mathematical manipulation of Eq. (2) that based on the definition of relative growth rate (R), the resulted function is written in Eq. (3).

$$
\frac{1}{y} \frac{d y}{d t}=\mathrm{k}\left(1-\frac{1}{a} y\right)
$$

Where, $\mathrm{R}=\mathrm{k}\left(1-\frac{1}{a} y\right)$.

BY solving differential equation of Eq. (3), the growth size ( $y$ ) over time at instant time is given by Eq. (4) as shown below:

$$
\mathrm{y}=\frac{a}{1+b e^{-k t}}
$$

When $\mathrm{b}=e^{d}$, then $d$ is the constant of integration [16], and the time constant ( $c$ ) could be computed by $\frac{1}{k}$ or $c=\frac{1}{k}$. When $\mathrm{t} \rightarrow \infty$, then $e^{-k t} \rightarrow 0$, and thus $\mathrm{y} \rightarrow a$, or approximately $\mathrm{y}=a$. The $a$ is population size under severe limiting environment or $a$ is $y$ maximum size of $y$ at very high $t . \quad$ At $t=0$, then $e^{-c t}=1$, and thus the number of organism is $\frac{a}{1+b}$, and it is basically a very small or minute number. The curve of Eq. (4) is usually called as the logistic or autocatalytic model [16]. 


\section{Responses resulted from Covic-19 infection.}

\section{(a) Model of cumulative cases over days}

In a situation of covid-19 virus pandemic in Malaysia, it is of almost impossible in counting the virus.

Thus, the numbers of infected patients (responses) or the covid-19 cases were used in the analysis. The data on cumulative covid-infected cases, recovery, fatality, and active cases; and daily cases over days as sourced from the daily updates by The Ministry of Health, Malaysia were used [26]. The above Eq. (4) was then used in modeling the responses (Covid-19 infected cases), i.e., by using $y$ as the cumulative cases. There are several non-linear models in describing growth, but in this analysis, Eq. (4) is used since it is the most popularly used model in describing numerically the growth of organisms. In this study, the data collected for the period of Jan 25 - Jun 17, 2020 were used. This data duration that equivalent to 145 days were observed to be in condition of the 'matured' stage of the pandemic, i.e., up to the region of the RMCO phase enforcement [26].

In making the model functioning for catering possible several number of serial-time-wise infestation cycles [or subsequent smaller cycle(s)], the model of Eq. (4) was extended in having the so called the $j$-logistic function. For example, the bi-logistic model was used by Meyer in his work in the field of diffusion of social phenomena [27]. The $j$-logistic function used in predicting cumulative number of cases $\left(y_{i}\right)$ is shown in Eq. (5).

$$
\begin{array}{ll}
y_{i}=\sum_{j=1}^{j=n} \frac{a_{j}}{1+b_{j} e^{-k_{j}\left(t_{i}-p_{j}\right)}} & \\
\text { where } & t_{i}=\mathrm{i}_{\text {th }} \text { day, } \\
& a_{j}=\mathrm{j}_{\mathrm{th}} \text { partial asymptotic cases within } \mathrm{j}_{\mathrm{th}} \text { infection wave, } \\
& b_{j}, k_{j}, p_{j}=j_{t h} b, k, \text { and } p \text { constants within } j_{\text {th }} \text { infection wave. }
\end{array}
$$


The $p_{j}$ value was the number of days that showed the beginning of observed significant $j_{\text {th }}$ wave. The $p_{j}$ value is similar to 'IF' statement in mathematical operation but with the exception of without the presence of physical branching in one continuous mathematical function [28]. Thus, the effective day durations for cycle 1 was $\mathrm{t}=\left(p_{1}+1\right.$ to $\left.p_{2}-1\right)$ days, and for cycle 2 was $\mathrm{t}=\left(p_{2}\right.$ to $\left.p_{3}-1\right)$ days, for cycle $3, \mathrm{t}=$ $\left(p_{3}\right.$ to $\left.p_{4}-1\right)$ days, and finally for cycle $\mathrm{j}$ was $\mathrm{t}=\left(p_{j}\right.$ to $\left.\infty\right)$ days. At cycle $1, p_{1}=0$ since the analysis started from day $=1$. For cycles 2,3 , and $j$, the nets of relative days $\left(t-p_{j}\right)$ would be 0 , and consequently the cycle would have 'extremely' small effect $\left(y_{i}\right)$ of cycle $e_{j-1}$. In the analysis, mathematically Eq.(5) would be in operation within the range of day $=1$ to days $=\infty$.

The innovation of analytical method was made in having that at $j=1$ (first infection cycle), the yi would progress logistically from the point of $t_{i}=p_{1}+1$ and it would be approaching the asymptotic value $\left(y_{\text {asymptotic_1 } 1}\right)$ or $a_{1}\left(\rightarrow a_{1}\right)$ when $t_{i}$ approaching and beyond $p_{2}$ days as computed by using $a_{1}, b_{1}$, $k_{1}$ and $p_{1}$ constants. Subsequently, within $j_{2}$ [second cycle), the computation of $y_{i}$ would be using values of constants of $a_{2}, b_{2}, k_{2}$, and $p_{2}$. Within the $j_{2}$ cycle, if $t_{i}<$ or $=p_{2}$, the $y_{i} \rightarrow$ is $a_{2} /\left(1+b_{2}\right)$ at $a_{1}$-elevated $y$-axis. Starting from point of $t_{i}=p_{2}$, the $y_{i}$ would move in the 'new' logistic function and it would be approaching to $a_{2}$ asymptotic value $\left(y_{\text {asymptotic_2 }}\right)$ as $t_{i}$ approaching and beyond $p_{3}$ days. This $a_{2}$ was an additional or partial asymptotic value, and thus the new asymptotic value or cases from these two cycles of infestation would be $a_{1}+a_{2}$. The above systematic computation would be similarly applied for the possible additional cycle occurrences.

\section{(b) Daily cases vs. days model}

By taking the derivative of Eq. (5), the predicted daily increment of cases $\left[\left(\frac{d y}{d t}\right)_{i}\right]$ at $i_{t h}$ day was computed by model of Eq. (6). 


$$
\left(\frac{d y}{d t}\right)_{i}=\sum_{j=1}^{j=n} \frac{a_{j} b_{j} k_{j} e^{-k_{j}\left(t_{i}-p_{j}\right)}}{\left(1+b_{j} e^{-k_{j}\left(t_{i}-p_{j}\right)}\right)^{2}}
$$

The subscripts were as shown in Eq. (5).

With the anticipation of several additional or cycles of occurrences of covid-19 pandemic in Malaysia, approaches of discussion in the cumulative cases vs. days were similarly applicable to the discussion of progressive movement of the daily cases versus days. One cycle would represent one 'bell shape' distribution of daily cases versus days. The predicted curve of Eq. (6) with $j=n$ would have $n$ serial 'bell shape' curves indicating the presence of $n$ additional cycles of Covid-19 pandemic. The curve that had highest peak with widest tail-spread of density distribution would be the primary or main cycle among other smaller cycles.

\section{(c) Inflection point and time constant}

By considering on only non-layered logistic model [Eq. (4)], the inflection point ( Ip) and time of inflection occurrence $\left(T_{\text {inf }}\right)$ could be computed by functions of $I p=a / 2$ and $T$ inf $=\log _{\mathrm{e}} b / k$, respectively. The inflection point is the point of the occurrence of changes between the increasing and decreasing daily

rates in the cumulative cases over days. The daily rate $\left(\frac{d y}{d t}\right)$ was maximum at time $T_{\text {inf }}$ or when $d^{2} y /(d t)^{2}=0$

In an exponential decay curve of $y=y_{o} e^{-b t}$, where $y_{0}$ is the maximum value, and $y$ and $t$ are the dependent variable and time, respectively, and thus, the reciprocal of constant $k$, i.e., $c=\frac{1}{k}$ is the time constant [29]. At point when $\mathrm{t}=c$ (unit: $\mathrm{t}^{-1}$ ), then $\mathrm{y}=\mathrm{y}_{0} \mathrm{e}^{-1}$ and yielding $\mathrm{y}=\mathrm{y}_{0}{ }^{*} 0.368$ since $\mathrm{e}^{-1}=0.368$. This illustrates the needed t value for reducing $y$ value to $36.8 \%$ of $y_{o}$, and thus, this time constant could be used in measuring the speed of the decay. By mathematical manipulation, Eq. (4) could be rewritten as 
$\left(\frac{a}{y}-1\right)=b e^{-k t}$. Since $a$ is constant, the $c=\frac{1}{k}$ is time constant in reducing $\left(\frac{a}{y}-1\right)$ to $36.8 \%$ of $b$ or relatively speaking of increasing $\mathrm{y}$. In this study, the time constant relative to the $a$ value would also be used descriptively in comparing the aggressiveness of infection of primary pandemic cycle to the subsequent serial additional cycle(s).

\section{(d) Models of recovery and fatality.}

The fractions of cumulative recoveries and fatalities over cumulative cases were used in modeling the recovery and fatality versus days. Due to the complementarity between recovery and fatality, and for having positive incremental percentages over days, the fraction were computed based on the total of partial asymptotic cases $\left(a_{\text {total }}\right)$ that sourced from the j cycles as shown in Eq. (7).

$$
a_{\text {total }}=\sum_{j=1}^{j=n} a_{j}
$$

Where $a_{j}=j_{t h}$ asymptotic value.

The models used for predicting the fractions of recovery $\left(y r_{i}\right)$ and fatality $\left(y f_{i}\right)$ over days were similar to the form and associated conditions of Eq. (5). The respective constants would then be $a r_{j}$, $b r_{j}, p r_{j}$, and $k r_{j}$; and $a f_{j}, b f_{j}, p f_{j}$, and $k f_{j}$ for recovery and fatality, respectively. The functions used in computing predicted accumulative recovery $\left(p y r_{i}\right)$ and fatality $\left(p y f_{i}\right)$ at $i_{\text {th }}$ day are indicated in Eqs. (8) and (9), respectively.

$$
\begin{aligned}
& \text { pyr }_{i}=y r_{i} * a_{\text {total }} \\
& \text { pyf }_{i}=y f_{i} * a_{\text {total }}
\end{aligned}
$$

\section{(e) Model of active cases.}

The cumulative active or remaining cases at $i_{t h}$ day was computed by deducting the cumulative recovery and fatality from the cumulative cases. The active cases are cases that still having covid-19 infection and 
they are probably contagious to other susceptible individuals. Thus, the predicted active cases at $i_{t h}$ day $\left(\right.$ active $_{i}$ ) could be computed by Eq. (5) - Eq. (8) - Eq. (9). In full, the model could be rewritten as shown in Eq. (10).

$$
\begin{gathered}
\text { active }_{i}=\sum_{j=1}^{j=n} \frac{a_{j}}{1+b_{j} e^{-k_{j}\left(t_{i}-p_{j}\right)}}-a_{\text {total }}\left\{\left(\sum_{j=1}^{j=n} \frac{a r_{j}}{1+b r_{j} e^{-k r_{j}\left(t_{i}-p r_{j}\right)}}\right)+\right. \\
\left.\left(\sum_{j=1}^{j=n} \frac{a f_{j}}{1+b f_{j} e^{-k f_{j}\left(t_{i}-p f_{j}\right)}}\right)\right\}
\end{gathered}
$$

The respective subscripts in the model are as above indicated.

\section{(f) Model fitting and additional analyses}

In this study, the model fitness was analyzed by computing coefficient of determination $\left(R^{2}\right)$. For models of Eqs. (5), (8), and (9), the $R^{2}$ values were computed by using the model and total sum of squares of the non-liner model. The regression technique of observed data vs. predicted data was used in computing $\mathrm{R}^{2}$ for models of Eqs. (6) and (10). The one-way analysis of variance (ANOVA) and the LSD test were carried out for daily cases that sourced from importation, local Malaysian citizens, and local foreigners of the May 18 - June 17, 2020 data. This was carried out in determining the main causes of the additional cycle occurrence.

\section{Data collection and statistical analysis tools.}

Data (Jan. 25 - Jun. 17, 2020) that sourced from the Ministry of Health, Malaysia were used in this analysis [26]. The data on cumulative cases, recovery, and fatality were used in computing the daily cases, recoveries, and fatalities. Additionally, the daily cases that based on importation, local Malaysian citizens, and local foreigners during May 18 - June 17, 2020 were also recorded. The statistical analyses 
(inclusive of the graphic presentations) were executed by writing SAS programming of SAS9.4 version statistical package [30].

\section{Results and Discussions}

\section{Cumulative and daily cases}

As earlier stated, this analysis were made based on the positive covid-19 infection cases of cumulative cases, recoveries, and fatalities over days; and the associated daily cases. It was not based on the number of tests or screening made on the target groups or communities. Based on the collected data of Jan. $25-$ Jun. 17, 2020, Figure 1 shows the curve of cumulative cases over days that resulted from the model shown in Eq. (5) with its associated values of constants indicated in Table 1. The respective observed and predicted data over days are given in Table 2.The model was significantly fitted to the observed cases with $R^{2}=99.9 \%(p<0.0001)$.

As up to Jun. 17, 2020, Figure 1 shows that the curve contained additional serial smaller cycles of infestation. At this point, we could say that the analysis shows the covid-19 pandemic in Malaysia was made up from primary cycle and two additional serial cycles of pandemic as the predicted outputs were highly fitted to the observed values. Based on the dynamic curve (daily cases curve), the left and right tails of cycle 2 are mixed with the cycle1 right-tail and cycle3 left-tail, respectively. In general, the primary cycle mainly occurred for the period of Jan. 25 - Apr. 19, 2020, while the other two serial two additional cycles occurred during Apr. 20 -May 17, 2020 and May 18,2020 and onwards, respectively. In this study, it was felt logical (due to the shown curvature) that the first or primary cycle $(j=1)$ was basically made up of initially declared waves that occurring during Jan. 25 - Feb. 28 and Feb. 29 - Apr. 19, 2020 with its partial asymptotic cases $\left(a_{1}\right)$ of 5,889 (Table 1$)$. The respective partial $a_{j}$ values for the second $(j=2)$ and third ( $\mathrm{j}=3$ ) cycles were 968 and 1,643 cases, respectively. Thus, the $a_{\text {total }}$ value of model (Eq. (7)) was 


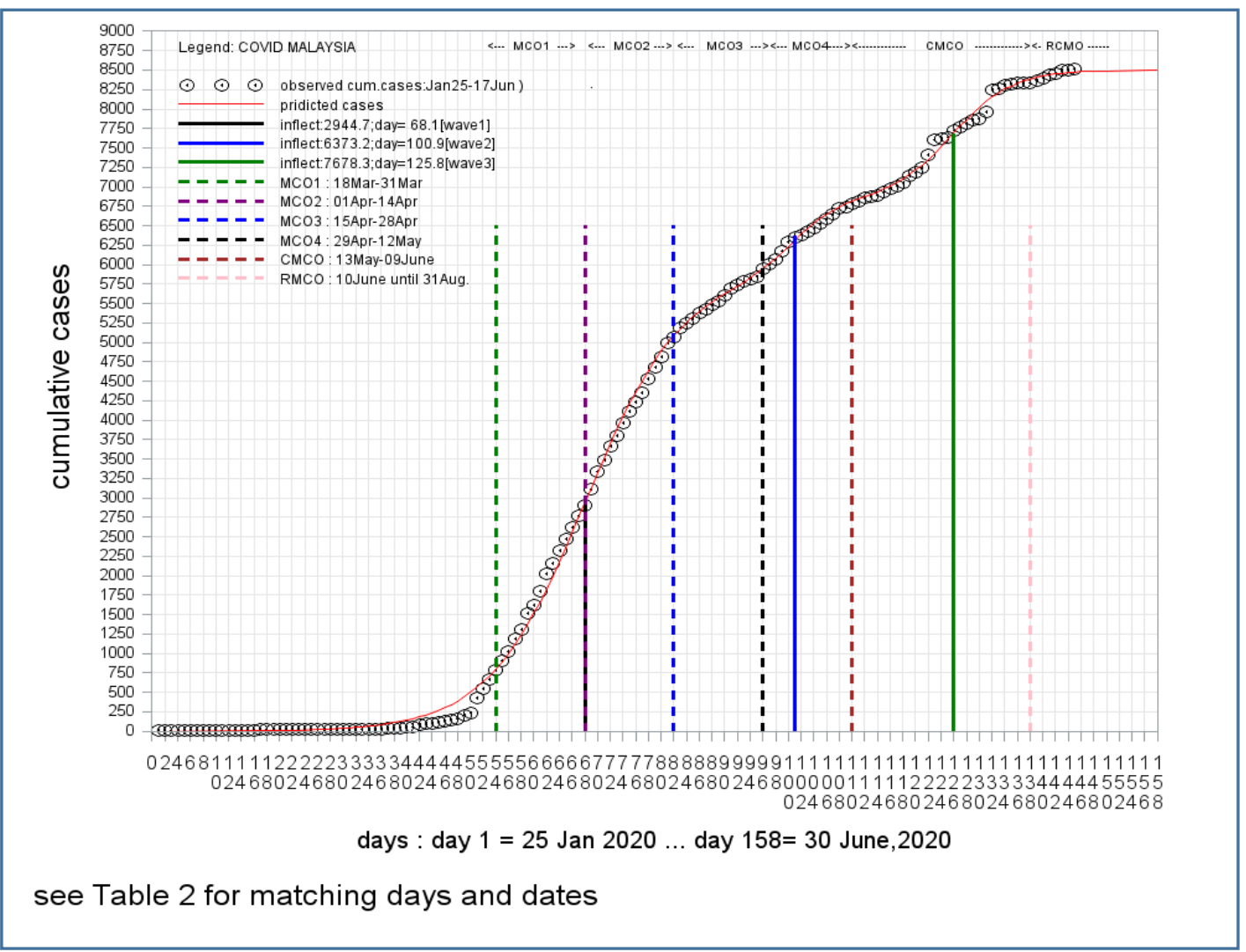

Figure 1: The observed and predicted of cumulative covid-19 cases over days in six movement control order (MCO) phases during the period of Jan. 25 - Jun. 17, 2020 and Jan. 25 - Jun. 30, 2020, respectively. The vertical solid lines are referenced to inflection points of the primary cycle (cycle 1 ), cycle 2 , and cycle 3 as indicated in the Figure.

8,500 cases. By inserting values in Table 1 into Eq. (5), the tri-logistic model is explicitly written as shown in Eq. (11). The presence of these smaller additional cycles would be evidently seen in the following discussion that based on the predicted daily cases as the first derivative of Eq. (5) [Figure 2 and Eqs. (6 and 12)] since the derivative function would be more sensitive in showing the dynamic of the pandemic [3]. 
Table 1: The constants, day constant, inflection point, day of inflection, and maximum predicted daily covid cases as related to the tri-logistic function of Eq. (5).

\begin{tabular}{|c|c|c|c|c|c|c|c|c|}
\hline Cycle & $a$ & $b$ & $k$ & $p$ & $\begin{array}{c}\text { day } \\
\text { constant } \\
C \\
\end{array}$ & $\begin{array}{l}\text { inflection } \\
\text { point } \\
(I p)\end{array}$ & $\begin{array}{l}\text { day of inflection } \\
\left(T_{\text {inf }}\right)\end{array}$ & $\begin{array}{c}\text { Max .predicted } \\
\text { daily cases }\end{array}$ \\
\hline 1 & $5,889.4$ & $7,961.13$ & 0.1320 & 0 & 7.58 & $2,944.7$ & 68.1 & 194.3 \\
\hline 2 & 967.6 & 5.17074 & 0.2776 & 95 & 3.60 & 483.8 & 100.9 & 78.7 \\
\hline 3 & $1,642.5$ & 19.708 & 0.2153 & 112 & 4.64 & 821.2 & 125.8 & 89.1 \\
\hline
\end{tabular}

Notes: $\{1\} a=$ partial asymptomatic value, model $a_{\text {total }}=8,499.5$ cases.

(2) The inflections points of cycles 2 and 3 are measured form $a$ values of cycle 1 and cycles $1+2$, respectively.

(3) The day of inflection of cycle 2 and 3 were computed by $\log _{\mathrm{e}} b_{2} / k_{2}+p_{2}$ and $\log _{\mathrm{e}} b_{3} / k_{3}+p_{3}$, respectively.

$$
y_{i}=\frac{5889.4}{1+7961.13 e^{-0.1320\left(t_{i}-0\right)}}+\frac{967.6}{5.17074 e^{-0.2776\left(t_{i}-95\right)}}+\frac{1642.5}{1+19.708 e^{-0.2153\left(t_{i}-112\right)}}
$$

where $y_{i}=$ predicted cumulative cases at $i_{\text {th }}$ day,

$$
t_{i}=i_{\text {th }} \text { day. }
$$

As shown by Figure 1 and Table 2, the observed cases were little bit higher at days=141 -145 (Jun. 13 17) than the predicted cumulative cases by $0.07 \%-0.49 \%$. This would probably suggest that, in spite of in this rehabilitation MCO (RCMO), there are possibly still 'small 'amount of resources (environmental factors and hosts) available for Covid-19 infection and additionally with small import cases. Also, at this higher region of days, the number of cases of the local foreigner workers is quite 'significant'. Thus, the study suggests that the actions and intervention of $\mathrm{MCO}$ (RCMO) should be appropriately maintained during the pandemic. The enforcement of RMCO until August 31, 2020 is then appropriate. With the current effective covid mitigating (under RMCO), it is expected the cumulative cases over days would not much higher over the model $a_{\text {total }}$ (8,500 cases) in the postdate days of the study period. 
Table 2: The observed and predicted data of covid pandemic of Jan. 25 - Jun.17 (145 days) and Jan. 25 Jun. 30 (158 days), respectively in Malaysia as computed by Eqs. (5, 6, 8, 9, and 10).

\begin{tabular}{|c|c|c|c|c|c|c|c|c|c|c|c|c|c|}
\hline day & Date & $\begin{array}{l}\text { cumulative } \\
\text { cases }\end{array}$ & $\begin{array}{l}\text { cumulative } \\
\text { recovery }\end{array}$ & $\begin{array}{l}\text { cumulative } \\
\text { fatality }\end{array}$ & $\begin{array}{l}\text { daily } \\
\text { cases }\end{array}$ & $\begin{array}{c}\text { predicted } \\
\text { cumulative } \\
\text { cases }\end{array}$ & $\begin{array}{l}\text { predicted } \\
\text { daily cases }\end{array}$ & $\begin{array}{l}\text { Predicted } \\
\text { cum. } \\
\text { recovery } \\
\text { cases }\end{array}$ & $\begin{array}{l}\text { Predicted } \\
\text { cum. } \\
\text { fatality } \\
\text { cases }\end{array}$ & $\begin{array}{l}\text { Cumulative } \\
\text { active cases }\end{array}$ & $\begin{array}{l}\text { Predicted } \\
\text { cum. active } \\
\text { cases }\end{array}$ & $\begin{array}{c}\% \text { cum. } \\
\text { recovery } \\
\text { based on } \\
\text { instant } \\
\text { cases }\end{array}$ & $\begin{array}{c}\% \text { cum. } \\
\text { fatality } \\
\text { based on } \\
\text { instant } \\
\text { cases }\end{array}$ \\
\hline 1 & $1 \_25$ & 3 & 0 & 0 & . & 0.8 & 0.1 & 0.0 & 0.0 & 3 & 0.8 & 0.00 & 0.00 \\
\hline 2 & 1_26 & 4 & 0 & 0 & 1 & 1.0 & 0.1 & 0.0 & 0.0 & 4 & 0.9 & 0.00 & 0.00 \\
\hline 3 & 1_27 & 4 & 0 & 0 & 0 & 1.1 & 0.1 & 0.0 & 0.0 & 4 & 1.1 & 0.00 & 0.00 \\
\hline 4 & 1_28 & 7 & 0 & 0 & 3 & 1.3 & 0.2 & 0.0 & 0.0 & 7 & 1.2 & 0.00 & 0.00 \\
\hline 5 & 1_29 & 7 & 0 & 0 & 0 & 1.4 & 0.2 & 0.0 & 0.0 & 7 & 1.4 & 0.00 & 0.00 \\
\hline 6 & 1_30 & 8 & 0 & 0 & 1 & 1.6 & 0.2 & 0.0 & 0.0 & 8 & 1.6 & 0.00 & 0.00 \\
\hline 7 & 1_31 & 8 & 0 & 0 & 0 & 1.9 & 0.2 & 0.0 & 0.0 & 8 & 1.8 & 0.00 & 0.00 \\
\hline 8 & 2_01 & 8 & 0 & 0 & 0 & 2.1 & 0.3 & 0.0 & 0.0 & 8 & 2.1 & 0.00 & 0.00 \\
\hline 9 & 2_02 & 8 & 0 & 0 & 0 & 2.4 & 0.3 & 0.1 & 0.0 & 8 & 2.4 & 0.00 & 0.00 \\
\hline 10 & $2 \_03$ & 8 & 0 & 0 & 0 & 2.8 & 0.4 & 0.1 & 0.0 & 8 & 2.7 & 0.00 & 0.00 \\
\hline 11 & 2_04 & 10 & 1 & 0 & 2 & 3.2 & 0.4 & 0.1 & 0.0 & 9 & 3.1 & 10.00 & 0.00 \\
\hline 12 & 2_05 & 12 & 1 & 0 & 2 & 3.6 & 0.5 & 0.1 & 0.0 & 11 & 3.5 & 8.33 & 0.00 \\
\hline 13 & 2_06 & 14 & 1 & 0 & 2 & 4.1 & 0.5 & 0.1 & 0.0 & 13 & 4.0 & 7.14 & 0.00 \\
\hline 14 & 2_07 & 14 & 1 & 0 & 0 & 4.7 & 0.6 & 0.1 & 0.0 & 13 & 4.6 & 7.14 & 0.00 \\
\hline 15 & 2_08 & 16 & 2 & 0 & 2 & 5.3 & 0.7 & 0.1 & 0.0 & 14 & 5.2 & 12.50 & 0.00 \\
\hline 16 & 2_09 & 17 & 3 & 0 & 1 & 6.1 & 0.8 & 0.2 & 0.0 & 14 & 5.9 & 17.65 & 0.00 \\
\hline 17 & 2_10 & 18 & 3 & 0 & 1 & 7.0 & 0.9 & 0.2 & 0.0 & 15 & 6.7 & 16.67 & 0.00 \\
\hline 18 & 2_11 & 18 & 3 & 0 & 0 & 7.9 & 1.0 & 0.2 & 0.0 & 15 & 7.7 & 16.67 & 0.00 \\
\hline 19 & 2_12 & 18 & 3 & 0 & 0 & 9.1 & 1.2 & 0.3 & 0.0 & 15 & 8.8 & 16.67 & 0.00 \\
\hline 20 & 2_13 & 19 & 3 & 0 & 1 & 10.3 & 1.4 & 0.3 & 0.0 & 16 & 10.0 & 15.79 & 0.00 \\
\hline 21 & 2_14 & 19 & 7 & 0 & 0 & 11.8 & 1.6 & 0.4 & 0.0 & 12 & 11.4 & 36.84 & 0.00 \\
\hline 22 & 2_15 & 21 & 7 & 0 & 2 & 13.5 & 1.8 & 0.4 & 0.0 & 14 & 13.0 & 33.33 & 0.00 \\
\hline 23 & 2_16 & 22 & 8 & 0 & 1 & 15.3 & 2.0 & 0.5 & 0.1 & 14 & 14.8 & 36.36 & 0.00 \\
\hline 24 & 2_17 & 22 & 9 & 0 & 0 & 17.5 & 2.3 & 0.6 & 0.1 & 13 & 16.8 & 40.91 & 0.00 \\
\hline 25 & 2_18 & 22 & 11 & 0 & 0 & 20.0 & 2.6 & 0.7 & 0.1 & 11 & 19.2 & 50.00 & 0.00 \\
\hline 26 & 2_19 & 22 & 15 & 0 & 0 & 22.8 & 3.0 & 0.8 & 0.1 & 7 & 21.9 & 68.18 & 0.00 \\
\hline 27 & $2 \_20$ & 22 & 17 & 0 & 0 & 26.0 & 3.4 & 1.0 & 0.1 & 5 & 24.9 & 77.27 & 0.00 \\
\hline 28 & 2_21 & 22 & 17 & 0 & 0 & 29.6 & 3.9 & 1.2 & 0.1 & 5 & 28.3 & 77.27 & 0.00 \\
\hline 29 & $2 \_22$ & 22 & 17 & 0 & 0 & 33.8 & 4.4 & 1.4 & 0.1 & 5 & 32.3 & 77.27 & 0.00 \\
\hline 30 & 2_23 & 22 & 18 & 0 & 0 & 38.5 & 5.0 & 1.6 & 0.2 & 4 & 36.8 & 81.82 & 0.00 \\
\hline 31 & $2 \_24$ & 22 & 20 & 0 & 0 & 43.9 & 5.7 & 1.9 & 0.2 & 2 & 41.8 & 90.91 & 0.00 \\
\hline 32 & 2_25 & 22 & 20 & 0 & 0 & 50.0 & 6.5 & 2.2 & 0.2 & 2 & 47.6 & 90.91 & 0.00 \\
\hline 33 & $2 \_26$ & 22 & 20 & 0 & 0 & 57.0 & 7.5 & 2.6 & 0.3 & 2 & 54.2 & 90.91 & 0.00 \\
\hline 34 & 2_27 & 24 & 22 & 0 & 2 & 65.0 & 8.5 & 3.0 & 0.3 & 2 & 61.6 & 91.67 & 0.00 \\
\hline 35 & 2_28 & 25 & 22 & 0 & 1 & 74.0 & 9.6 & 3.6 & 0.4 & 3 & 70.1 & 88.00 & 0.00 \\
\hline 36 & 2_29 & 29 & 22 & 0 & 4 & 84.3 & 11.0 & 4.2 & 0.4 & 7 & 79.7 & 75.86 & 0.00 \\
\hline
\end{tabular}




\begin{tabular}{|c|c|c|c|c|c|c|c|c|c|c|c|c|c|}
\hline day & Date & $\begin{array}{l}\text { cumulative } \\
\text { cases }\end{array}$ & $\begin{array}{c}\text { cumulative } \\
\text { recovery }\end{array}$ & $\begin{array}{l}\text { cumulative } \\
\text { fatality }\end{array}$ & $\begin{array}{l}\text { daily } \\
\text { cases }\end{array}$ & $\begin{array}{l}\text { predicted } \\
\text { cumulative } \\
\text { cases }\end{array}$ & $\begin{array}{l}\text { predicted } \\
\text { daily cases }\end{array}$ & $\begin{array}{l}\text { Predicted } \\
\text { cum. } \\
\text { recovery } \\
\text { cases }\end{array}$ & $\begin{array}{l}\text { Predicted } \\
\text { cum. } \\
\text { fatality } \\
\text { cases }\end{array}$ & $\begin{array}{l}\text { Cumulative } \\
\text { active cases }\end{array}$ & $\begin{array}{l}\text { Predicted } \\
\text { cum. active } \\
\text { cases }\end{array}$ & $\begin{array}{c}\% \text { cum. } \\
\text { recovery } \\
\text { based on } \\
\text { instant } \\
\text { cases }\end{array}$ & $\begin{array}{c}\% \text { cum. } \\
\text { fatality } \\
\text { based on } \\
\text { instant } \\
\text { cases }\end{array}$ \\
\hline 37 & 3_01 & 33 & 22 & 0 & 4 & 96.0 & 12.5 & 4.9 & 0.5 & 11 & 90.6 & 66.67 & 0.00 \\
\hline 38 & 3_02 & 33 & 22 & 0 & 0 & 109.3 & 14.2 & 5.8 & 0.6 & 11 & 103.0 & 66.67 & 0.00 \\
\hline 39 & 3_03 & 36 & 22 & 0 & 3 & 124.4 & 16.1 & 6.8 & 0.7 & 14 & 117.0 & 61.11 & 0.00 \\
\hline 40 & 3_04 & 50 & 22 & 0 & 14 & 141.6 & 18.2 & 8.0 & 0.8 & 28 & 132.8 & 44.00 & 0.00 \\
\hline 41 & 3_05 & 55 & 22 & 0 & 5 & 161.0 & 20.7 & 9.4 & 0.9 & 33 & 150.7 & 40.00 & 0.00 \\
\hline 42 & 3_06 & 83 & 22 & 0 & 28 & 183.0 & 23.4 & 11.0 & 1.1 & 61 & 170.9 & 26.51 & 0.00 \\
\hline 43 & 3_07 & 93 & 23 & 0 & 10 & 207.9 & 26.5 & 12.9 & 1.3 & 70 & 193.7 & 24.73 & 0.00 \\
\hline 44 & 3_08 & 99 & 24 & 0 & 6 & 236.0 & 29.9 & 15.2 & 1.5 & 75 & 219.3 & 24.24 & 0.00 \\
\hline 45 & 3_09 & 117 & 24 & 0 & 18 & 267.8 & 33.7 & 17.8 & 1.8 & 93 & 248.2 & 20.51 & 0.00 \\
\hline 46 & 3_10 & 129 & 25 & 0 & 12 & 303.6 & 38.0 & 20.9 & 2.1 & 104 & 280.6 & 19.38 & 0.00 \\
\hline 47 & 3_11 & 149 & 26 & 0 & 20 & 344.0 & 42.7 & 24.6 & 2.4 & 123 & 316.9 & 17.45 & 0.00 \\
\hline 48 & 3_12 & 158 & 32 & 0 & 9 & 389.3 & 48.0 & 28.8 & 2.9 & 126 & 357.6 & 20.25 & 0.00 \\
\hline 49 & 3_13 & 203 & 32 & 0 & 45 & 440.1 & 53.7 & 33.8 & 3.4 & 171 & 402.9 & 15.76 & 0.00 \\
\hline 50 & 3_14 & 238 & 35 & 0 & 35 & 496.9 & 60.0 & 39.7 & 3.9 & 203 & 453.3 & 14.71 & 0.00 \\
\hline 51 & 3_15 & 428 & 42 & 0 & 190 & 560.4 & 66.9 & 46.6 & 4.6 & 386 & 509.2 & 9.81 & 0.00 \\
\hline 52 & 3_16 & 553 & 42 & 0 & 125 & 630.9 & 74.3 & 54.6 & 5.3 & 511 & 571.0 & 7.59 & 0.00 \\
\hline 53 & 3_17 & 673 & 49 & 2 & 120 & 709.2 & 82.3 & 64.1 & 6.2 & 622 & 638.9 & 7.28 & 0.30 \\
\hline 54 & 3_18 & 790 & 60 & 3 & 117 & 795.7 & 90.8 & 75.1 & 7.2 & 727 & 713.4 & 7.59 & 0.38 \\
\hline 55 & 3_19 & 900 & 75 & 3 & 110 & 891.0 & 99.8 & 88.0 & 8.4 & 822 & 794.7 & 8.33 & 0.33 \\
\hline 56 & 3_20 & 1030 & 87 & 4 & 130 & 995.5 & 109.2 & 103.0 & 9.7 & 939 & 882.8 & 8.45 & 0.39 \\
\hline 57 & 3_21 & 1183 & 114 & 8 & 153 & 1109.4 & 118.8 & 120.5 & 11.2 & 1061 & 977.7 & 9.64 & 0.68 \\
\hline 58 & 3_22 & 1306 & 139 & 11 & 123 & 1233.2 & 128.7 & 140.9 & 13.0 & 1156 & 1079.3 & 10.64 & 0.84 \\
\hline 59 & 3_23 & 1518 & 159 & 14 & 212 & 1366.7 & 138.5 & 164.6 & 14.9 & 1345 & 1187.3 & 10.47 & 0.92 \\
\hline 60 & 3_24 & 1624 & 183 & 16 & 106 & 1510.1 & 148.2 & 192.1 & 17.1 & 1425 & 1301.0 & 11.27 & 0.99 \\
\hline 61 & 3_25 & 1796 & 199 & 20 & 172 & 1663.0 & 157.5 & 223.9 & 19.5 & 1577 & 1419.6 & 11.08 & 1.11 \\
\hline 62 & 3_26 & 2031 & 215 & 25 & 235 & 1824.9 & 166.2 & 260.7 & 22.1 & 1791 & 1542.1 & 10.59 & 1.23 \\
\hline 63 & 3_27 & 2161 & 259 & 26 & 130 & 1995.1 & 174.1 & 303.1 & 25.0 & 1876 & 1667.0 & 11.99 & 1.20 \\
\hline 64 & 3_28 & 2320 & 320 & 33 & 159 & 2172.7 & 180.9 & 351.7 & 28.1 & 1967 & 1792.9 & 13.79 & 1.42 \\
\hline 65 & 3_29 & 2470 & 388 & 35 & 150 & 2356.6 & 186.6 & 407.3 & 31.5 & 2047 & 1917.8 & 15.71 & 1.42 \\
\hline 66 & 3_30 & 2626 & 479 & 37 & 156 & 2545.4 & 190.7 & 470.7 & 35.0 & 2110 & 2039.7 & 18.24 & 1.41 \\
\hline 67 & 3_31 & 2766 & 537 & 43 & 140 & 2737.5 & 193.4 & 542.5 & 38.7 & 2186 & 2156.4 & 19.41 & 1.55 \\
\hline 68 & 4_01 & 2908 & 645 & 45 & 142 & 2931.5 & 194.3 & 623.4 & 42.5 & 2218 & 2265.6 & 22.18 & 1.55 \\
\hline 69 & 4_02 & 3116 & 767 & 50 & 208 & 3125.6 & 193.6 & 714.0 & 46.4 & 2299 & 2365.2 & 24.61 & 1.60 \\
\hline 70 & 4_03 & 3333 & 827 & 53 & 217 & 3318.2 & 191.2 & 814.9 & 50.3 & 2453 & 2453.0 & 24.81 & 1.59 \\
\hline 71 & 4_04 & 3483 & 915 & 57 & 150 & 3507.5 & 187.3 & 926.1 & 54.2 & 2511 & 2527.2 & 26.27 & 1.64 \\
\hline 72 & 4_05 & 3662 & 1005 & 61 & 179 & 3692.2 & 181.9 & 1047.9 & 58.0 & 2596 & 2586.3 & 27.44 & 1.67 \\
\hline 73 & 4_06 & 3793 & 1241 & 62 & 131 & 3870.9 & 175.2 & 1180.0 & 61.7 & 2490 & 2629.2 & 32.72 & 1.63 \\
\hline 74 & 4_07 & 3963 & 1321 & 63 & 170 & 4042.3 & 167.5 & 1321.8 & 65.2 & 2579 & 2655.3 & 33.33 & 1.59 \\
\hline
\end{tabular}




\begin{tabular}{|c|c|c|c|c|c|c|c|c|c|c|c|c|c|}
\hline day & Date & $\begin{array}{l}\text { cumulative } \\
\text { cases }\end{array}$ & $\begin{array}{c}\text { cumulative } \\
\text { recovery }\end{array}$ & $\begin{array}{l}\text { cumulative } \\
\text { fatality }\end{array}$ & $\begin{array}{l}\text { daily } \\
\text { cases }\end{array}$ & $\begin{array}{l}\text { predicted } \\
\text { cumulative } \\
\text { cases }\end{array}$ & $\begin{array}{l}\text { predicted } \\
\text { daily cases }\end{array}$ & $\begin{array}{l}\text { Predicted } \\
\text { cum. } \\
\text { recovery } \\
\text { cases }\end{array}$ & $\begin{array}{l}\text { Predicted } \\
\text { cum. } \\
\text { fatality } \\
\text { cases }\end{array}$ & $\begin{array}{l}\text { Cumulative } \\
\text { active cases }\end{array}$ & $\begin{array}{l}\text { Predicted } \\
\text { cum. active } \\
\text { cases }\end{array}$ & $\begin{array}{c}\text { \% cum. } \\
\text { recovery } \\
\text { based on } \\
\text { instant } \\
\text { cases }\end{array}$ & $\begin{array}{c}\% \text { cum. } \\
\text { fatality } \\
\text { based on } \\
\text { instant } \\
\text { cases }\end{array}$ \\
\hline 75 & 4_08 & 4119 & 1487 & 65 & 156 & 4205.5 & 158.9 & 1472.3 & 68.5 & 2567 & 2664.7 & 36.10 & 1.58 \\
\hline 76 & 4_09 & 4228 & 1608 & 67 & 109 & 4359.9 & 149.8 & 1630.3 & 71.6 & 2553 & 2658.0 & 38.03 & 1.58 \\
\hline 77 & 4_10 & 4346 & 1830 & 70 & 118 & 4504.9 & 140.2 & 1794.2 & 74.5 & 2446 & 2636.2 & 42.11 & 1.61 \\
\hline 78 & 4_11 & 4530 & 1995 & 73 & 184 & 4640.3 & 130.5 & 1962.1 & 77.1 & 2462 & 2601.0 & 44.04 & 1.61 \\
\hline 79 & 4_12 & 4683 & 2108 & 76 & 153 & 4765.9 & 120.8 & 2131.9 & 79.5 & 2499 & 2554.4 & 45.01 & 1.62 \\
\hline 80 & 4_13 & 4817 & 2276 & 77 & 134 & 4881.9 & 111.3 & 2301.5 & 81.7 & 2464 & 2498.7 & 47.25 & 1.60 \\
\hline 81 & 4_14 & 4987 & 2478 & 82 & 170 & 4988.6 & 102.1 & 2468.7 & 83.7 & 2427 & 2436.2 & 49.69 & 1.64 \\
\hline 82 & 4_15 & 5072 & 2647 & 83 & 85 & 5086.3 & 93.4 & 2631.6 & 85.4 & 2342 & 2369.3 & 52.19 & 1.64 \\
\hline 83 & 4_16 & 5182 & 2766 & 84 & 110 & 5175.7 & 85.3 & 2788.4 & 87.0 & 2332 & 2300.3 & 53.38 & 1.62 \\
\hline 84 & 4_17 & 5251 & 2967 & 86 & 69 & 5257.2 & 77.9 & 2937.6 & 88.4 & 2198 & 2231.2 & 56.50 & 1.64 \\
\hline 85 & 4_18 & 5305 & 3102 & 88 & 54 & 5331.6 & 71.1 & 3078.3 & 89.6 & 2115 & 2163.7 & 58.47 & 1.66 \\
\hline 86 & 4_19 & 5389 & 3197 & 89 & 84 & 5399.7 & 65.2 & 3209.6 & 90.8 & 2103 & 2099.3 & 59.32 & 1.65 \\
\hline 87 & 4_20 & 5425 & 3295 & 89 & 36 & 5462.2 & 60.1 & 3331.4 & 91.8 & 2041 & 2039.0 & 60.74 & 1.64 \\
\hline 88 & 4_21 & 5482 & 3349 & 92 & 57 & 5520.1 & 55.9 & 3443.7 & 92.8 & 2041 & 1983.6 & 61.09 & 1.68 \\
\hline 89 & 4_22 & 5532 & 3452 & 93 & 50 & 5574.3 & 52.7 & 3546.8 & 93.7 & 1987 & 1933.7 & 62.40 & 1.68 \\
\hline 90 & 4_23 & 5603 & 3542 & 95 & 71 & 5625.8 & 50.6 & 3641.6 & 94.7 & 1966 & 1889.6 & 63.22 & 1.70 \\
\hline 91 & 4_24 & 5691 & 3663 & 96 & 88 & 5675.8 & 49.6 & 3728.8 & 95.6 & 1932 & 1851.4 & 64.36 & 1.69 \\
\hline 92 & 4_25 & 5742 & 3762 & 98 & 51 & 5725.5 & 49.9 & 3809.8 & 96.5 & 1882 & 1819.1 & 65.52 & 1.71 \\
\hline 93 & 4_26 & 5780 & 3862 & 98 & 38 & 5776.0 & 51.4 & 3885.8 & 97.5 & 1820 & 1792.6 & 66.82 & 1.70 \\
\hline 94 & 4_27 & 5820 & 3957 & 99 & 40 & 5828.6 & 54.1 & 3958.4 & 98.6 & 1764 & 1771.6 & 67.99 & 1.70 \\
\hline$\underline{95}$ & $\underline{428}$ & $\underline{5851}$ & $\underline{4032}$ & $\underline{100}$ & $\underline{31}$ & $\underline{5884.5}$ & $\underline{58.0}$ & 4029.3 & $\underline{99.7}$ & $\underline{1719}$ & $\underline{1755.5}$ & $\underline{68.91}$ & $\underline{1.71}$ \\
\hline 96 & 4_29 & 5945 & 4087 & 100 & 94 & 5944.8 & 62.6 & 4100.2 & 100.9 & 1758 & 1743.7 & 68.75 & 1.68 \\
\hline 97 & 4_30 & 6002 & 4171 & 102 & 57 & 6009.9 & 67.7 & 4172.9 & 102.1 & 1729 & 1735.0 & 69.49 & 1.70 \\
\hline 98 & 5_01 & 6071 & 4210 & 103 & 69 & 6080.1 & 72.5 & 4249.0 & 103.3 & 1758 & 1727.8 & 69.35 & 1.70 \\
\hline 99 & 5_02 & 6170 & 4320 & 103 & 99 & 6154.7 & 76.4 & 4330.2 & 104.4 & 1747 & 1720.1 & 70.02 & 1.67 \\
\hline 100 & 5_03 & 6298 & 4413 & 105 & 128 & 6232.3 & 78.6 & 4417.4 & 105.5 & 1780 & 1709.4 & 70.07 & 1.67 \\
\hline 101 & 5_04 & 6353 & 4484 & 105 & 55 & 6311.1 & 78.6 & 4511.1 & 106.5 & 1764 & 1693.5 & 70.58 & 1.65 \\
\hline 102 & 5_05 & 6383 & 4567 & 106 & 30 & 6388.8 & 76.4 & 4610.9 & 107.3 & 1710 & 1670.5 & 71.55 & 1.66 \\
\hline 103 & 5_06 & 6428 & 4702 & 107 & 45 & 6463.1 & 72.0 & 4715.5 & 108.1 & 1619 & 1639.5 & 73.15 & 1.66 \\
\hline 104 & 5_07 & 6467 & 4776 & 107 & 39 & 6532.2 & 66.0 & 4822.7 & 108.7 & 1584 & 1600.8 & 73.85 & 1.65 \\
\hline 105 & 5_08 & 6535 & 4864 & 107 & 68 & 6594.9 & 59.2 & 4929.8 & 109.3 & 1564 & 1555.8 & 74.43 & 1.64 \\
\hline 106 & 5_09 & 6589 & 4929 & 108 & 54 & 6650.6 & 52.3 & 5033.9 & 109.7 & 1552 & 1506.9 & 74.81 & 1.64 \\
\hline 107 & 5_10 & 6656 & 5025 & 108 & 67 & 6699.6 & 45.8 & 5132.5 & 110.1 & 1523 & 1457.0 & 75.50 & 1.62 \\
\hline 108 & 5_11 & 6726 & 5113 & 109 & 70 & 6742.5 & 40.2 & 5223.6 & 110.5 & 1504 & 1408.4 & 76.02 & 1.62 \\
\hline 109 & 5_12 & 6742 & 5223 & 109 & 16 & 6780.3 & 35.7 & 5306.1 & 110.8 & 1410 & 1363.5 & 77.47 & 1.62 \\
\hline 110 & 5_13 & 6779 & 5281 & 111 & 37 & 6814.3 & 32.5 & 5379.8 & 111.0 & 1387 & 1323.5 & 77.90 & 1.64 \\
\hline 111 & 5_14 & 6819 & 5351 & 112 & 40 & 6845.7 & 30.6 & 5445.1 & 111.2 & 1356 & 1289.4 & 78.47 & 1.64 \\
\hline 112 & 5_15 & 6855 & 5439 & 112 & 36 & 6875.9 & 29.9 & 5502.9 & 111.4 & 1304 & 1261.5 & 79.34 & 1.63 \\
\hline
\end{tabular}




\begin{tabular}{|c|c|c|c|c|c|c|c|c|c|c|c|c|c|}
\hline day & Date & $\begin{array}{l}\text { cumulative } \\
\text { cases }\end{array}$ & $\begin{array}{l}\text { cumulative } \\
\text { recovery }\end{array}$ & $\begin{array}{l}\text { cumulative } \\
\text { fatality }\end{array}$ & $\begin{array}{l}\text { daily } \\
\text { cases }\end{array}$ & $\begin{array}{c}\text { predicted } \\
\text { cumulative } \\
\text { cases }\end{array}$ & $\begin{array}{l}\text { predicted } \\
\text { daily cases }\end{array}$ & $\begin{array}{l}\text { Predicted } \\
\text { cum. } \\
\text { recovery } \\
\text { cases }\end{array}$ & $\begin{array}{l}\text { Predicted } \\
\text { cum. } \\
\text { fatality } \\
\text { cases }\end{array}$ & $\begin{array}{l}\text { Cumulative } \\
\text { active cases }\end{array}$ & $\begin{array}{l}\text { Predicted } \\
\text { cum. active } \\
\text { cases }\end{array}$ & $\begin{array}{l}\text { \% cum. } \\
\text { recovery } \\
\text { based on } \\
\text { instant } \\
\text { cases }\end{array}$ & $\begin{array}{c}\text { \% cum. } \\
\text { fatality } \\
\text { based on } \\
\text { instant } \\
\text { cases }\end{array}$ \\
\hline 113 & 5_16 & 6872 & 5512 & 113 & 17 & 6906.0 & 30.5 & 5554.5 & 111.6 & 1247 & 1239.9 & 80.21 & 1.64 \\
\hline 114 & 5_17 & 6894 & 5571 & 113 & 22 & 6937.3 & 32.3 & 5601.1 & 111.8 & 1210 & 1224.4 & 80.81 & 1.64 \\
\hline$\underline{115}$ & $\underline{5 \quad 18}$ & $\underline{6941}$ & 5615 & 113 & 47 & 6971.0 & 35.2 & 5644.2 & 112.0 & 1213 & 1214.8 & 80.90 & 1.63 \\
\hline 116 & 5_19 & 6978 & 5646 & 114 & 37 & 7008.1 & 39.2 & 5684.8 & 112.2 & 1218 & 1211.1 & 80.91 & 1.63 \\
\hline 117 & 5_20 & 7009 & 5706 & 114 & 31 & 7049.7 & 44.1 & 5724.2 & 112.4 & 1189 & 1213.1 & 81.41 & 1.63 \\
\hline 118 & 5_21 & 7059 & 5796 & 114 & 50 & 7096.7 & 49.9 & 5763.2 & 112.5 & 1149 & 1220.9 & 82.11 & 1.61 \\
\hline 119 & 5_22 & 7137 & 5859 & 115 & 78 & 7149.7 & 56.3 & 5802.8 & 112.7 & 1163 & 1234.2 & 82.09 & 1.61 \\
\hline 120 & $5 \_23$ & 7185 & 5912 & 115 & 48 & 7209.4 & 63.1 & 5843.6 & 112.9 & 1158 & 1252.9 & 82.28 & 1.60 \\
\hline 121 & $5 \_24$ & 7245 & 5945 & 115 & 60 & 7275.9 & 69.9 & 5886.2 & 113.1 & 1185 & 1276.6 & 82.06 & 1.59 \\
\hline 122 & 5_25 & 7417 & 5979 & 115 & 172 & 7349.0 & 76.2 & 5931.2 & 113.4 & 1323 & 1304.5 & 80.61 & 1.55 \\
\hline 123 & 5_26 & 7604 & 6041 & 115 & 187 & 7428.1 & 81.8 & 5978.9 & 113.6 & 1448 & 1335.6 & 79.45 & 1.51 \\
\hline 124 & 5_27 & 7619 & 6083 & 115 & 15 & 7512.1 & 85.9 & 6029.8 & 113.8 & 1421 & 1368.5 & 79.84 & 1.51 \\
\hline 125 & 5_28 & 7629 & 6169 & 115 & 10 & 7599.5 & 88.5 & 6084.0 & 114.1 & 1345 & 1401.4 & 80.86 & 1.51 \\
\hline 126 & 5_29 & 7732 & 6235 & 115 & 103 & 7688.4 & 89.0 & 6141.8 & 114.3 & 1382 & 1432.2 & 80.64 & 1.49 \\
\hline 127 & 5_30 & 7762 & 6330 & 115 & 30 & 7776.8 & 87.6 & 6203.3 & 114.6 & 1317 & 1458.9 & 81.55 & 1.48 \\
\hline 128 & 5_31 & 7819 & 6353 & 115 & 57 & 7862.9 & 84.3 & 6268.5 & 114.9 & 1351 & 1479.5 & 81.25 & 1.47 \\
\hline 129 & $6 \_01$ & 7857 & 6404 & 115 & 38 & 7944.8 & 79.3 & 6337.3 & 115.2 & 1338 & 1492.3 & 81.51 & 1.46 \\
\hline 130 & $6 \_02$ & 7877 & 6470 & 115 & 20 & 8021.1 & 73.1 & 6409.6 & 115.5 & 1292 & 1496.0 & 82.14 & 1.46 \\
\hline 131 & $6 \_03$ & 7970 & 6531 & 115 & 93 & 8090.8 & 66.2 & 6485.2 & 115.8 & 1324 & 1489.8 & 81.94 & 1.44 \\
\hline 132 & 6_04 & 8247 & 6559 & 115 & 277 & 8153.4 & 58.9 & 6563.7 & 116.2 & 1573 & 1473.5 & 79.53 & 1.39 \\
\hline 133 & 6_05 & 8266 & 6610 & 116 & 19 & 8208.6 & 51.6 & 6644.7 & 116.5 & 1540 & 1447.3 & 79.97 & 1.40 \\
\hline 134 & 6_06 & 8303 & 6635 & 117 & 37 & 8256.6 & 44.6 & 6727.8 & 116.9 & 1551 & 1411.9 & 79.91 & 1.41 \\
\hline 135 & 6_07 & 8322 & 6674 & 117 & 19 & 8297.9 & 38.1 & 6812.5 & 117.3 & 1531 & 1368.1 & 80.20 & 1.41 \\
\hline 136 & 6_08 & 8329 & 6694 & 117 & 7 & 8333.0 & 32.2 & 6898.1 & 117.7 & 1518 & 1317.2 & 80.37 & 1.40 \\
\hline 137 & $6 \_09$ & 8336 & 6975 & 117 & 7 & 8362.5 & 27.0 & 6984.0 & 118.1 & 1244 & 1260.5 & 83.67 & 1.40 \\
\hline 138 & $6 \_10$ & 8338 & 7014 & 118 & 2 & 8387.2 & 22.5 & 7069.7 & 118.5 & 1206 & 1199.1 & 84.12 & 1.42 \\
\hline 139 & 6_11 & 8369 & 7065 & 118 & 31 & 8407.8 & 18.6 & 7154.4 & 118.9 & 1186 & 1134.4 & 84.42 & 1.41 \\
\hline 140 & $6 \_12$ & 8402 & 7168 & 119 & 33 & 8424.7 & 15.4 & 7237.7 & 119.3 & 1115 & 1067.7 & 85.31 & 1.42 \\
\hline 141 & $6 \_13$ & 8445 & 7311 & 120 & 43 & 8438.7 & 12.6 & 7318.9 & 119.8 & 1014 & 999.9 & 86.57 & 1.42 \\
\hline 142 & $6 \_14$ & 8453 & 7346 & 121 & 8 & 8450.1 & 10.3 & 7397.6 & 120.2 & 986 & 932.2 & 86.90 & 1.43 \\
\hline 143 & 6_15 & 8494 & 7400 & 121 & 41 & 8459.4 & 8.4 & 7473.3 & 120.7 & 973 & 865.4 & 87.12 & 1.42 \\
\hline 144 & $6 \_16$ & 8505 & 7733 & 121 & 11 & 8467.0 & 6.9 & 7545.7 & 121.2 & 651 & 800.2 & 90.92 & 1.42 \\
\hline 145 & 6_17 & 8515 & 7873 & 121 & 10 & 8473.2 & 5.6 & 7614.4 & 121.6 & 521 & 737.1 & 92.46 & 1.42 \\
\hline 146 & $6 \_18$ & . & . & . & . & 8478.2 & 4.5 & 7679.4 & 122.1 & . & 676.8 & . & . \\
\hline 147 & $6 \_19$ & . & . & . & . & 8482.3 & 3.7 & 7740.4 & 122.6 & . & 619.4 & . & . \\
\hline 148 & $6 \_20$ & . & . & . & . & 8485.6 & 3.0 & 7797.4 & 123.1 & . & 565.2 & . & . \\
\hline 149 & $6 \_21$ & . & . & . & . & 8488.3 & 2.4 & 7850.3 & 123.6 & . & 514.4 & . & . \\
\hline 150 & $6 \_22$ & . & . & . & . & 8490.5 & 1.9 & 7899.4 & 124.0 & . & 467.0 & . & . \\
\hline
\end{tabular}




\begin{tabular}{|c|c|c|c|c|c|c|c|c|c|c|c|c|c|}
\hline day & Date & $\begin{array}{c}\text { cumulative } \\
\text { cases }\end{array}$ & $\begin{array}{c}\text { cumulative } \\
\text { recovery }\end{array}$ & $\begin{array}{l}\text { cumulative } \\
\text { fatality }\end{array}$ & $\begin{array}{l}\text { daily } \\
\text { cases }\end{array}$ & $\begin{array}{l}\text { predicted } \\
\text { cumulative } \\
\text { cases }\end{array}$ & $\begin{array}{c}\text { predicted } \\
\text { daily cases }\end{array}$ & $\begin{array}{l}\text { Predicted } \\
\text { cum. } \\
\text { recovery } \\
\text { cases }\end{array}$ & $\begin{array}{l}\text { Predicted } \\
\text { cum. } \\
\text { fatality } \\
\text { cases }\end{array}$ & $\begin{array}{l}\text { Cumulative } \\
\text { active cases }\end{array}$ & $\begin{array}{l}\text { Predicted } \\
\text { cum. active } \\
\text { cases }\end{array}$ & $\begin{array}{c}\text { \% cum. } \\
\text { recovery } \\
\text { based on } \\
\text { instant } \\
\text { cases }\end{array}$ & $\begin{array}{c}\% \text { cum. } \\
\text { fatality } \\
\text { based on } \\
\text { instant } \\
\text { cases }\end{array}$ \\
\hline 151 & $6 \_23$ & . & . & . & . & 8492.2 & 1.6 & 7944.6 & 124.5 & . & 423.1 & . & . \\
\hline 152 & $6 \_24$ & . & . & . & . & 8493.6 & 1.3 & 7986.1 & 125.0 & . & 382.5 & . & . \\
\hline 153 & $6 \_25$ & . & . & . & . & 8494.8 & 1.0 & 8024.1 & 125.5 & . & 345.2 & . & . \\
\hline 154 & $6 \_26$ & . & . & . & . & 8495.7 & 0.8 & 8058.7 & 125.9 & . & 311.1 & . & . \\
\hline 155 & $6 \_27$ & . & . & . & . & 8496.4 & 0.7 & 8090.2 & 126.4 & . & 279.9 & . & . \\
\hline 156 & $6 \_28$ & . & . & . & . & 8497.0 & 0.5 & 8118.8 & 126.8 & . & 251.5 & . & . \\
\hline 157 & $6 \_29$ & . & . & . & . & 8497.5 & 0.4 & 8144.6 & 127.2 & . & 225.7 & . & . \\
\hline 158 & 6_30 & . & . & . & . & 8497.9 & 0.4 & 8167.9 & 127.7 & . & 202.4 & . & . \\
\hline
\end{tabular}

As based on the respective $y$-axes in the common curve, the inflection points of the primary

cycle (2,945 cases) was higher than those of the others two additional cycles (484 and 821 cases for

cycles 2 and 3, respectively) (Table1). Based on the starting points the $j_{\text {th }}$ cycles, the above trend was also

observed in the predicted days for the occurrence of inflection point (IT), where the respective values

were 68.1 days (68.1 days from Jan. 25), 100.9 days (13.9 days from Apr. 28), and 125.8 days (5.9 days

from May 15). At these points of days, the predicted maximum daily cases for cycles 1, 2, and 3 were

194.3, 78.7, and 89.1 cases day-1, respectively (Figure 2 and Table 1). By using Table 1 and Eq. (6) that

yielded from the first derivatives of Eq. (5), the tri-logistic related function of the predicted daily rate is

explicitly written as shown in Eq. (12). The fitness of the model was significant with $R^{2}=70.4 \%(n=144, p<$

0.04). The fluctuation of the observed daily cases moved around along the predicted curve. The

occurrences of one primary and two additional cycles in the pandemic dynamic were clearly indicated in

Figure 2 that showing three 'bell shape' curves ( with three amplitudes) of predicted daily cases versus

days as the derivative of function is more sensitive in determining the dynamic as compared of

cumulative cases versus days. 


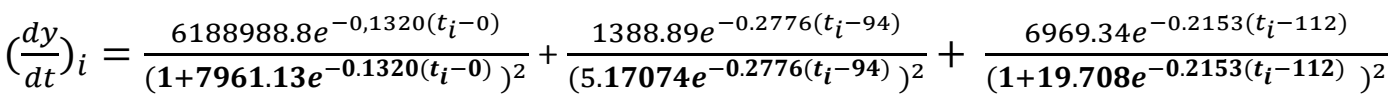

$$
\begin{aligned}
& \text { where }\left(\frac{d y}{d t}\right)_{i}=\text { predicted daily cases at ith day, }
\end{aligned}
$$

By taking the reciprocal of $k_{j}$, the day constant was computed $\left(c_{j}=1 / k_{j}\right)$. The $c_{j}$ values for first, second, and third cycles were 7.58, 3.60, and 4.64 day $^{-1}$, respectively (Table 1). As based on the relation of $c_{j}$ and $a_{j} / y_{j}$ value, it shows that the cycles 2 and 3 were faster in reaching the respective $a_{j}$ values that that of cycle 1 , but the $a_{j}$ values for cycles 2 and 3 were much lower than that of cycle 1 . By considering simultaneously the values of $a_{j}, T_{i n f}, c_{j}$, and the respective predicted maximum daily cases, the primary cycle or cycle 1 was more aggressive in covid-19 pandemic than the other two cycles (Figures 1 and 2). The first derivative was sufficient in indicating the sensitivity of the pandemic during the study period, and thus the second derivative in computing the dynamic acceleration and deceleration were not computed in this study. The middle cycle (cycle 2) was affected by the Cycles 1 and 2 . The actions taken by the government (several stages of movement control order (MCO) and followed by the conditional) imposed nationwide had resulted encouraging positive results in managing the pandemic that only yielding two subsequent additional smaller or weaker cycles. The Ministry have indicated that the extension of MCO into phase 4 would enable the Ministry to work towards completely eradicating the transmission of Covid-19 [31]. The MCO listed among others were 'stay at home', 'no interstate travelling', 'social distancing', 'self-hygiene awareness and practices' , 'controlling and restricting international travelling', and actively upgrading and operating the covid-19 screenings or tests and health related facilities and pandemic treatment in designated public and private hospitals. As of today (June 17, 2020), the government is enforcing the rehabilitation MCO due the down trending of daily cases, cumulative active cases, and reaching the mode of cumulative cases plateauing. 
Being a tropical country (annual mean temperature and humidity of $27^{\circ} \mathrm{C}$ and $>80 \%$, respectively) [32], Malaysia's high temperature and humidity had probably made the MCO effective in controlling and mitigating the covid-19 pandemic. Even though it is still debatable, it is probably that the virus spread and infection would be lower by higher temperature and humidity. As indicated in Hong Kong, the risk of severe acute respiratory syndrome (SARS) infection would be at 18 folds higher in daily cases at lower temperature versus higher temperature [33]. In term of SARS viability, it will rapidly lost at higher temperature and humidity indicating the virus transmission is more favorable in sub-tropical versus tropical countries [34]. As of SARS-CoV-2 (covid-19 virus), warmer temperatures are associated with lower rate of Covid-19, but with modest effect [35]. In other developments, the results (not yet peerreviewed) show that the weather of cold and dry apparently will boost the spread of covid-19 virus [36]. The medical expert from Taiwan warns of the covid-19 reoccurrence during the coming winter, and if the prevention intervention is not made, the pandemic would be getting worst [37].

The covid-19 infection in Malaysia is probably and highly due to the person-to-person contact rather than the contacts with physical surfaces that has virus droplets within an environment, locality or residential/business premises. By using data of May 18 - June 17, 2020 (coincided with the cycle 3 pandemic), the mean \pm standard error of daily cases of local foreigners, imports, and local citizen were $38.1+10.9,7.2 \pm 1.2$, and $6.9 \pm 0.8$ cases, respectively. The value for local foreigners was significantly higher than those of the imports and local citizen (LSD test at $p=0.05$ ). Thus, in cycle 3 , the local foreigners were the main source for cycle 3 occurrence. The imported cases were mainly sourced from those of citizens or permanent residents that returning home from various countries with covid-19 pandemic. These non-citizen locals are mainly workers in the manufacturing and construction industries, and in the supply and retail business. They are mainly staying in houses and hostels that mainly provided by their employers under 'crowded' occupancy condition that conducive for person-to-person contact for covid-19 infection. 


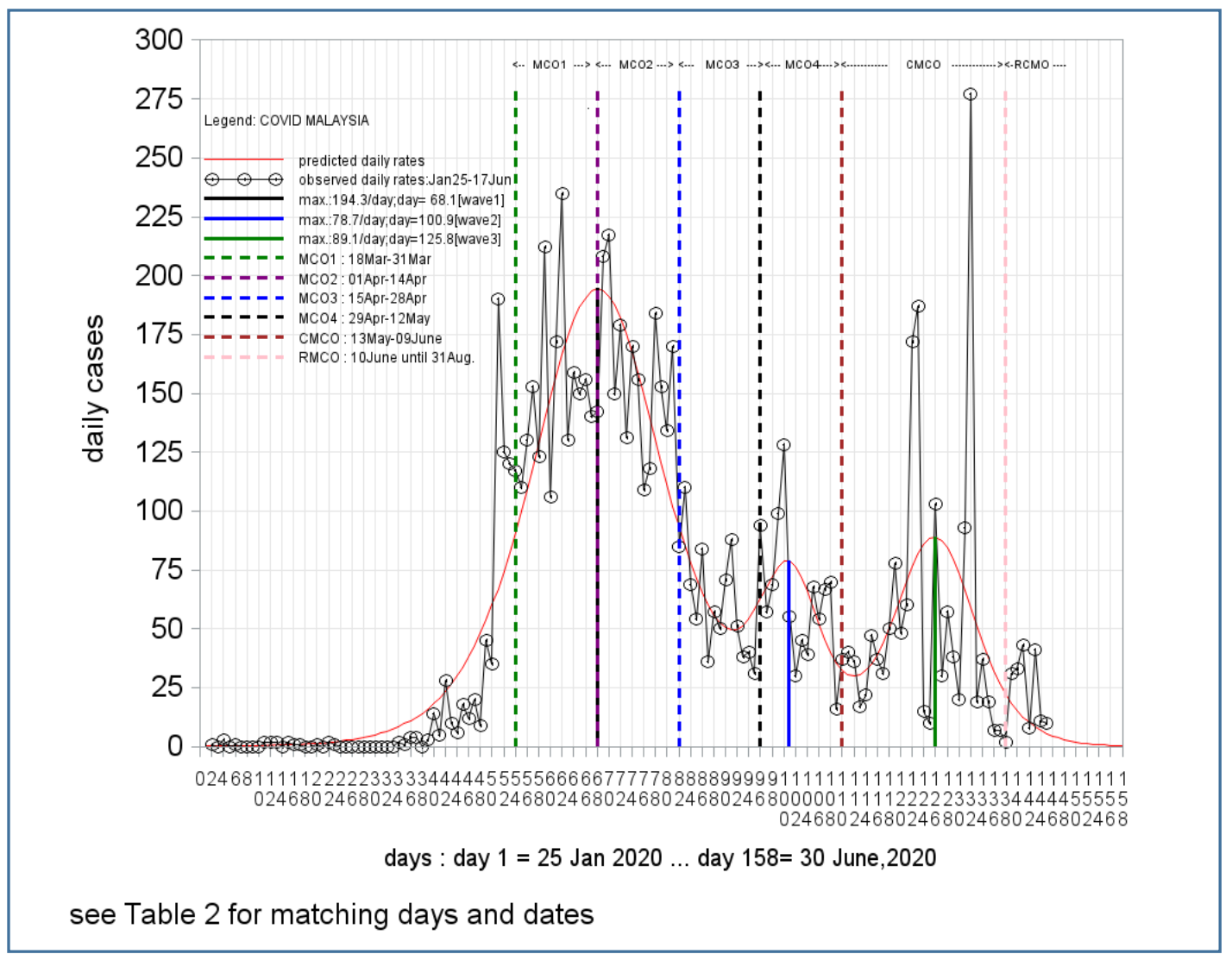

Figure 2: The observed and predicted daily covid-19 cases over days in six movement control order (MCO) phases during the period of Jan. 25 - Jun. 17, 2020 and Jan. 25 - Jun. 30, 2020, respectively. The vertical solid lines referenced to time of inflections that associated with the predicted daily maximum of the primary cycle (cycle 1), cycle 2, and cycle 3.

\section{Cumulative recovery and fatality cases}

Figure 3 shows the observed and predicted accumulative recovery and fatality cases over days that computed by Eqs. ( 8 and 9 ) and the associated data are indicated in Table 2. The respective constant values of the models are given in Table 3. Based on the constants and Eqs. (8 and 9), the equations that related to the tri-logistic function are explicitly written in Eqs. (13 and 14). The related $R^{2}$ values (model fitness) for both recovery and fatality models were $>99 \%(p<0.0001)$. The trends of these two models were in tandem with that of the cumulative cases vs. days. The day constant values (measuring speed of 
the dynamic) of recovery model for cycles 1,2 , and 3 were $6.2,3.7$, and 8.2 day $^{-1}$, respectively, while the respective values for the fatality were $6.1,3.6$, and 13.5 day $^{-1}$. These values were generally close to those of cumulative cases model. Specifically in cycle 3 , the $c_{j}$ value of recovery was lower than that of the fatality indicating recovery rate was faster than the fatality during the CMCO and RMCO phases. This could be interpreted as the results of the effective control interventions and efficient medical facilities and services made and provided by the government and her related agencies, especially the Ministry of Health and the enforcement bodies.

$$
\begin{aligned}
& \text { pyr }_{i}=8,499.5\left(\frac{0.4930}{1+355394 e^{-0,1614\left(t_{i}-0\right)}}+\frac{0.1573}{1+12.2512 e^{-0.2698\left(t_{i}-95\right)}}+\frac{0.3328}{1+19.7877 e^{-0.1214\left(t_{i}-112\right)}}\right) \\
& \text { py } f_{i}=8,499.5\left(\frac{0.0113}{1+80650.3 e^{-0.1627\left(t_{i}-0\right)}}+\frac{0.00165}{1+2.0142 e^{-0.2796\left(t_{i}-95\right)}}+\frac{0.00305}{1+14.2643 e^{-0.074\left(t_{i}-112\right)}}\right)
\end{aligned}
$$

Where pyr $_{i}=$ predicted cumulative recoveries at $i_{\text {th }}$ day,

$$
\begin{aligned}
& p y f_{i}=\text { predicted cumulative fatalities at } \mathrm{i}_{\mathrm{th}} \text { day, } \\
& t_{i}=\mathrm{i}_{\text {th }} \text { day. }
\end{aligned}
$$

The predicted percentages of recovery and fatality were computed by (predicted cumulative recovery/cumulative cases) $* 100 \%$ and (predicted cumulative fatality/cumulative cases)*100\%, respectively. Based on the trends shown in the analysis, the final percentages of recovery and fatality were estimated at $98.4 \%$ and $1.6 \%$, respectively. As at the end of this study period (June 17, 2020), the predicted recovery and fatality percentages were $89.4 \%$ and $1.43 \%$, respectively, while the respective observed percentages were $92.5 \%$ and $1.42 \%$. At the same date, as based on the reports of dated June 17,2020 , the global recovery and fatality were $52.4 \%$ and $5.38 \%$, respectively [ 1 ]. The respective figures for North America, Europe, and Asia were 43.9\% and 5.81\%; 53.3\% and 8.20\%; and 


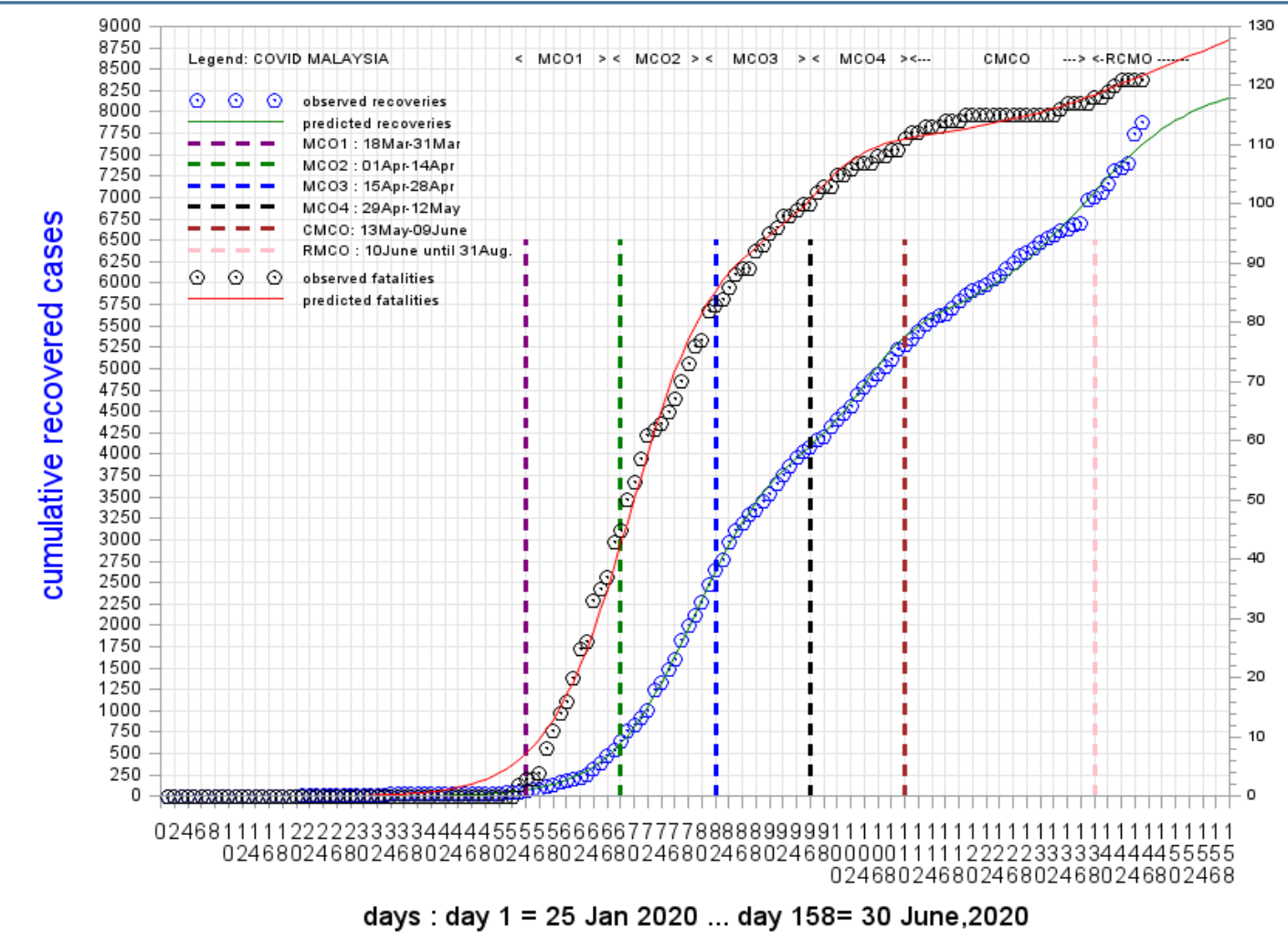

see Table 2 for matching days and dates

Figure 3: Observed (Jan. 25 - Jun. 17, 2020) and predicted (Jan. 25 - Jun. 30, 2020) cumulative recoveries and fatalities due to Covid-19 infestation in six MCO phases.

Table 3: The constants and day constant of recovery and fatality models that based on fraction of cumulative recoveries and fatality to the total asymptotic value of the cumulative cases vs. days.

\begin{tabular}{|c|c|c|c|c|c|c|c|c|c|c|}
\hline \multirow[b]{2}{*}{ Cycle } & \multicolumn{5}{|c|}{ Cumulative recovery model } & \multicolumn{5}{|c|}{ Cumulative fatality model } \\
\hline & a & b & k & $\begin{array}{c}\text { Day } \\
\text { constant } \\
\left(c_{j}\right)\end{array}$ & $\mathbf{p}$ & a & b & k & $\begin{array}{c}\text { Day } \\
\text { constant } \\
\left(c_{j}\right)\end{array}$ & $\mathbf{p}$ \\
\hline 1 & 0.4939 & 335394 & 0.1614 & 6.2 & 0 & 0.0113 & 80650.3 & 0.1627 & 6.1 & 0 \\
\hline 2 & 0.1573 & 12.2512 & 0.2698 & 3.7 & 95 & 0.00165 & 2.0142 & 0.2796 & 3.6 & 95 \\
\hline 3 & 0.3328 & 19.7877 & 0.1214 & 8.2 & 112 & 0.00305 & 14.2643 & 0.074 & 13.5 & 112 \\
\hline
\end{tabular}


$62.6 \%$ and $2.57 \%$. While in some countries, namely USA, Italy, Germany, Saudi Arabia, India, China, Iran, South Korea, and Singapore, the respective figures were $40.9 \%$ and 5.39\%; $75.2 \%$ and $14.49 \%$; $91.9 \%$ and $4.73 \% ; 64.9 \%$ and $0.78 \% ; 52.6 \%$ and $2.89 \% ; 94.2 \%$ and $5.57 \% ; 79.4 \%$ and $4.71 \% ; 88.3 \%$ and $2.29 \%$; and $76.1 \%$ and $0.06 \%$. Thus in general, Malaysia is among the countries that has higher recoveries and lower fatalities. The models of high and significant fitting to the recorded data had indicated that the trends of the increasing and decreasing of recoveries and fatalities, respectively were well synchronized and fitted to the enforcement of the MCO phases (Figure 3). In actual fact, the fatality rate should be lower since $80 \%$ of the fatalities were those simultaneously of having the chronic diseases (hypertension, diabetes, etc.) [38].

\section{Active cases}

Cumulative active cases are the net or resultant of covid-19 infected cases after subtracting the cumulative recoveries and fatalities from the cumulative cases. These cases could be contiguous to other susceptible persons or communities. Figure 5 shows the curve of cumulative cases computed based on Eq. (15) that generally and originally in the form of Eq. (10). The associated predicted and observed data are shown in Table 2.

$$
\begin{aligned}
& \text { active }_{i}=\frac{5889.4}{1+7961.13 e^{-0.1320\left(t_{i}-0\right)}}+\frac{967.6}{5.17074 e^{-0.2776\left(t_{i}-95\right)}}+\frac{1642.5}{1+19.708 e^{-0.2153\left(t_{i}-112\right)}}- \\
& 8,499.5\left(\frac{0.4930}{1+335394 e^{-0,1614\left(t_{i}-0\right)}}+\frac{0.1573}{1+12.2512 e^{-0.2698\left(t_{i}-95\right)}}+\frac{0.3328}{1+19.7877 e^{-0.1214\left(t_{i}-112\right)}}+\right. \\
& \left.\frac{0.0113}{1+80650.3 e^{-0.1627\left(t_{i}-0\right)}}+\frac{0.00165}{1+2.0142 e^{-0.2796\left(t_{i}-95\right)}}+\frac{0.00305}{1+14.2643 e^{-0.074\left(t_{i}-112\right)}}\right) \\
& \text { Where, } \text { active }_{i}=\text { cumulative active cases at } i_{\text {th }} \text { day, } \\
& t_{i}=i_{\text {th }} \text { day. }
\end{aligned}
$$

The predicted active cases were significantly fitted to the observed values with $R^{2}=97 \%(p<0.0001)$. The predicted cumulative value on April 14, 2020 (day=115) (beginning of MCO phase 3) estimated by the 
Ministry of Health, Malaysia was 2,033 cases (45\% of cumulative cases). This value was lower than the observed value ( 2400 cases: $50 \%$ of cumulative cases) and the predicted cases of Eq. (15) (2,333 cases: $48 \%$ of cumulative cases). This would indicate that the tri-logistic model was successfully developed in modeling covid-19 responses in term of active cases over days. The highest predicted cumulative active cases occurred in the MCO phase 2 (Cycle 1). This then down trended that subsequently followed by an increase that resulted small peak as related to the occurrence of an additional serial smaller cycle (cycle 2). It then continued for the down trend that subsequently once again experiencing a quite substantial amount of peaking occurred in the CMCO phase that associated to the occurrence of the third cycle of the pandemic. As discussed earlier, the cycle 3 was mainly caused by the cases of the local foreigners (workers). Thus, apart from the predicted daily model, the dynamic of the pandemic could also be seen or detected from the model of active cases. The changes of curve trend were affected by the occurrences of the smaller serial cycles (cycles 2 and 3) over days. On June 17, 2020, the predicted percentages of active cases was $8.6 \%$ of the predicted cumulative cases, while the observed record was $6.1 \%$. At this date, the percentage globally was $42.2 \%$, and the figures for Singapore and Indonesia were 24.3\% and 55.3\%, respectively. During the rehabilitation MCO phase, the forecast cumulative active cases on June 30,2020 would be 202 cases (2.4\% of predicted cumulative cases). 


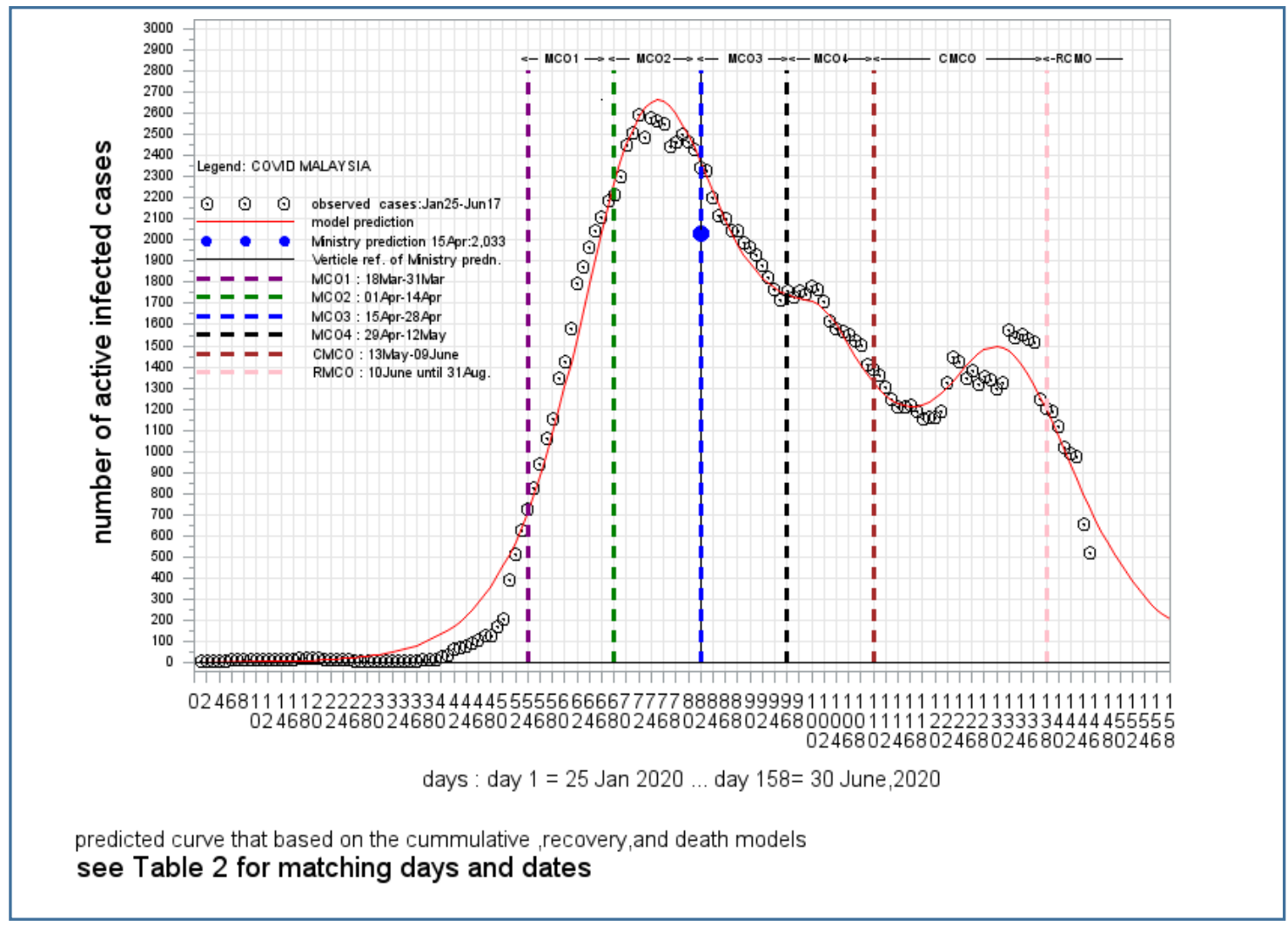

Figure 4: Observed (Jan. 25 - Jun. 17, 2020) and predicted (Jan. 25 - Jun. 30, 2020) cumulative active cases due to Covid-19 infestation in six MCO phases.

\section{Model linkages and tri-logistic model applicability}

The tri-logistic models of the recoveries and fatalities were linked to the cumulative cases function by

parameter of $a_{\text {total }}$ [Eq. (5) vs. Eqs. (7 and 8)]. On the other hand, the fractions of cumulative recoveries and fatalities had common denominator, i.e., $a_{\text {total }}$, and these two fractions were complement to each other since mathematically at the end season of the model ( at $t \rightarrow \infty$ ), the sum of them would be 1.0 or unity. Subsequently, active cases would be the resultant of Eq. (5) - Eq. (7) - Eq. (8). The accumulative ceases, recoveries, and fatalities models were highly fitted to the observed values with $R^{2}>99 \%$ at $p<$ 0.0001. The interconnected model as shown by the cumulative active cases was equally and highly fitted to the observed records with $R^{2}=97 \%(p<0.0001)$. The models were developed based by the approach of 
data driven that in contingent with the microbial growth model. The basic logistic function is used widely in the diverse fields including in the field of artificial neural network as its activation function. Thus, it could be concluded that the model used in this study could be used elsewhere currently or in the future in modeling the responses of covid-19 or covid-related epidemic/pandemic.

All the curves of responses were in tandem with the phases of four MCOs, CMCO, and RMCO, and thus indicating the validity of correctness and appropriateness of MCO enforcements in mitigating Covid-19 in Malaysia. The intervention (MCO enforcement) and health/medical/safety services and facilities should be synchronized and coordinated well in the objective of achieving stable $a_{\text {total }}$, since achieving the plateauing of cases is vital to systematically controlling, mitigating, and finally eradicating covid-19 pandemic of the Nation.

\section{Conclusion}

As indicated in the section of Introduction of this paper, the current wave is considered as only one wave that initially are consisted of wave 1( Jan 25- Feb.26) and wave 2 ( Feb. 27 and onwards). Within this reclassified one wave, the study has indicated that covid-19 in Malaysia has three cycles of the wave. They are the cycle $1\left(1^{\circ}\right.$ cycle) [Jan. 25 - Apr.27], cycle 2 [Apr. 28 - May 14] and cycle 3 [May 15 and onwards]. Above is evidenced by the following discussion.

There were three 'bell shape' curves in the dynamic model (derivative of cumulative cases vs. days) related to the pandemic cycles 1,2 , and 3 with the maximum predicted daily cases of $194.3,78.7$, and 89.1 cases day $^{-1}$, respectively. The respective days of occurrences of these maximums were 68.1, 100.9, and 125.8 days within the region of $\mathrm{MCO} 1 / \mathrm{MCO} 2, \mathrm{MCO} 4$, and $\mathrm{CMCO}$, respectively. These trends were 
also observed in the predicted cumulative active cases. Thus, the above had indicated the presence of the 3-cycle covid-19 pandemic in Malaysia. By integrating the above discussion with the day constant values ( cycles 1,2 , and $3: 7.6,3.6$, and 4.6 day $^{-1}$, respectively) relative to partial asymptotic cumulative cases ( cycles 1, 2, and $3: 5889,968$, and 1,643 cases, respectively), the aggressiveness among cycles were in the order of cycle1 > cycle $3>$ cycle 2 . As indicated in the findings, the occurrence of cycle 3 was mainly contributed by the high cases among local foreigners (workers). Thus, it is suggested the reallocation and remobilization of resources should be targeted in containing the covid-19 infection among the local foreigners while making surveillance activities continually among local citizens, especially in the phase of RCMO enforcement. Thus, the study has shown that by employing the proposed serial trinonlinear logistic growth model that developed based on data of Jan. 25 - Jun. 17, 2020 (145 days) and simultaneously in contingent with the consideration of the quantitative behavior of microbial population growth had been successful mathematically in identifying of the 3-cycle covid-19 pandemic in Malaysia. This partly shows the applicability of the function in modeling the responses of the pandemic in Malaysia.

Since the data duration used in this modeling study was considered as 'matured' (cumulative cases at about plateauing (evel), the forecasts on the daily cases and the cumulative figures of cases, recoveries, fatalities, and active cases at postdate days of the study period could be made. The predicted daily cases; the cumulative cases, recoveries, fatalities, and active cases at the end of the study period (June 17, 2020: 145 days) were 6 cases day-1 ; 8473, 7615, 122, and 737 cases, respectively. The respective observed figures were 10 cases day $^{-1} ; 8515,7873,121$, and 521 cases. The respective forecast values at June 30,

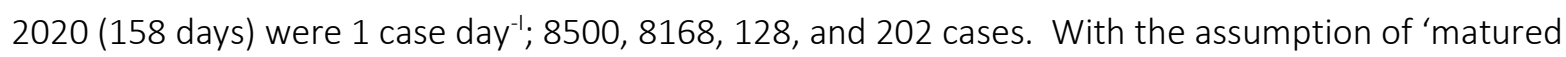
model', there would be a minimal more resources left for pandemic spread as indicated by the slight higher observed vs. predicted cumulative cases in the RMCO zone. This would caution the authority to stay alert in maintaining the MCO enforcement. If no any further odd-extraordinary cycle occurrence, the 
country would probably be enjoying a non-significant covid or 'covid-free' pandemic by the July end or mid-August, 2020.

The purposes of the enforcements of the movement control order (MCO) in several phases (phases $1-4$, conditional $\mathrm{MCO}$, enhanced $\mathrm{MCO}$, and rehabilitation $\mathrm{MCO}$ ) are generally to control and mitigate the spread of the pandemic, and specifically to reduce drastically the daily cases, the fatalities, and the active cases; and to increase the recoveries. The social distancing, self-hygiene, and having the 'new normal' ways of life are basically the centrals of the listed orders in the above MCOs. Even though it is still debatable, some researchers and workers have indicated that the activity and growth (replication) of viruses would be lower in the condition or environment of higher temperature and humidity. Being a tropical country, it is hypothesized or even 'predicted' that Malaysia would have an additive effect of MCO enforcement in mitigating covid-19 than those of the cooler countries. This could be seen as Malaysia is among the countries currently of having high recoveries and low fatalities. The predicted of all responses were tallied and in tandem to the objectives of MCO phases' enforcements. As in the RMCO, the observed and predicted values of daily cases and cumulative active cases were low, while the cumulative cases and recoveries were seemed at and about plateauing levels, respectively. Thus, this modeling study had indicated the validity of the correctness and appropriateness of the MCO phases' enforcements by the government.

The models were developed for the cumulative cases, recoveries, fatalities, and active cases vs. days; and daily cases vs. days. Based on cumulative records, the four models were related to each other by the key parameter of $a_{\text {total }}$ (asymptotic total), and the resultant model was indicated in the cumulative active cases model. Thus, basically, it was only one model in representing the variable of cases, recoveries, fatalities, and active cases. As indicated from the analyses, even though with high number of observations 
( $n=145$ ), yet each of the models of cumulative cases, recoveries, and fatalities vs. days had fitness of the R2 $>99 \%$ at $p<0.0001$, and the resultant model had R2 of $97 \%$ at $p<0.0001$. From the above exercise, it could be seen that the model involving the tri-logistic growth function (or even higher layered-logistic model) is unique in modeling responses of covid or covid-related pandemic/pandemic that involving several serial cycle of infections, and thus, this approach of the non-linear mathematical modeling could be used elsewhere. Additionally, the basic logistic growth function is used in the diverse fields of studies and applications. By knowing the valid estimates of respective parameters or constants, the model could be used for simulation purposes of the covid or covid-related epidemic or pandemic. Historically, the outputs of response model could probably used as guidelines of making action in mitigating future covid or covid-related infestation with the assumption of having quite 'similar' pattern of infestation even with the expected mutation of virus would be occurring in the future.

\section{References}

1. Worldometer: COVID-19 CORONAVIRUS PANDEMIC https://www.worldometers.info/coronavirus/?utm_campaign=homeAdvegas1?

Accessed 17 June, 2020

2. WHO Director-General's opening remarks at media briefing on Covid-19-11 March 2020 https://www.who.int/dg/speeches/detail/who-director-general-s-opening-remarks-at-the-mediabriefing-on-covid-19---11-march-2020

Accessed 18 June, 2020

3. Chen X, Yu B. First two months of the 2019 Coronavirus Disease (COVID-19) epidemic in China: real-time surveillance and evaluation with a second derivative model. glob health res policy 5, 7 (2020). https://doi.org/10.1186/s41256-020-00137-4

4. Malaysia confirms 3 Wuhan virus cases, who are relatives of Singapore's first imported case https://www.todayonline.com/world/health-minister-confirms-3-coronavirus-cases-malaysia. Accessed on 17 June, 2020. 
5. COVID-19 SITUATION OVERVIEW IN MALAYSIA.

https://www.who.int/docs/default-source/wpro---documents/countries/malaysia/coronavirusdisease-(covid-19)-situation-reports-in-malaysia/situation-report-malaysia-8-may-2020-

final.pdf?sfvrsn=ba5876cb_12

Accessed on 15 June, 2020

6. PRESS STATEMENT MINISTRY OF HEALTH MALAYSIA UPDATES ON THE CORONAVIRUS DISEASE 2019 (COVID-19) SITUATION IN MALAYSIA Current Situation of COVID-19 in Malaysia.

http://covid-19.moh.gov.my/terkini/032020/situasi-terkini-13-mac-2020/52\%20KPK\%20\%2013032020\%20-\%20EN.PDF

Accessed on 20 June, 2020

7. COVID-19 Weekly Round-up: Numbers Rising In Second Cycle https://www.bernama.com/en/features/news.php?id=1819036

Accessed on 20 June, 2020

8. Coronavirus: Malaysia cases rise by 190 after mosque event as imams urge online services. https://www.independent.co.uk/news/world/asia/coronavirus-malaysia-cases-southeast-asiamosque-islam-a9403816.html

Accessed on 20 June, 2020

9. Covid-19 pandemic in Malaysia. https://en.wikipedia.org/wiki/COVID-19_pandemic_in_Malaysia Assessed on 18 June, 2020

10. FAQ: 10 Things to know about the Conditional Movement Control Order in Malaysia https://www.buro247.my/lifestyle/news/conditional-movement-control-order-malaysia-faq.html Assed on 18 June, 2020

11. Star L, Moghadas SM. The role of Mathematical modelling in public health planning and decision making. National for Collaborating Centre for Infectious Diseases. Purple Paper, Issue no. 22, December 2010.

12. Christensen T, Painter M. The politics of SARS - Rational responses or ambiguity, symbols and chaos? Policy Soc. 2004;23:18-48

13. Sharomi O, Podder CN, Gumel AB, Mahmud SM, Rubinstein E. Modelling the transmission dynamics and control of the novel 2009 swine influenza (H1N1) pandemic. Bull Math Biol. 2011; 73:515-48.

14. Mangiarotti S, Peyre M, Huc M. A chaotic model for the epidemic of Ebola virus disease in West Africa (2013-2016). Chaos. Interdiscip J Nonlin Sci. 2016;26(11):113112. 
15. Engering A, Hogerwerf L, and Slingenbergh J. Pathogen-host-environment interplay and disease emergence. Emerg Microbes Infect. 2013 Feb; 2(2): e5. doi: 10.1038/emi.2013.5

16. Causton DR. A Biologist's Basic Mathematics. 1983. Edward Arnold (Great Britain, Australia, and USA).

17. Malato G. Covid-19 infection in Italy. Mathematical models and predictions. A comparison of logistic and exponential models applied to covid-19 virus in Italy. https://towardsdatascience.com/covid-19-infection-in-italy-mathematical-models-and-predictions$7784 b 4 d 7 d d 8 d$

Accessed June 23, 2020

18. Wu K, Darcet D, Wang Q, and Sornette D. Generalized logistic growth modeling of the COVID-19 outbreak in 29 provinces in China and in the rest of the world. DOI: 10.1101/2020.03.11.20034363 https://www.researchgate.net/publication/339898708_Generalized_logistic_growth_modeling of_the_COVID-19_outbreak_in_29_provinces_in_China_and_in_the_rest_of_the_world Accessed on 18 June, 2020

19. Schwartz S. The Mathematics behind the Coronavirus spread. http://www.mastermathmentor.com/mmm-archive/CoronaVirus.pdf Accessed 18 June, 2020.

20. Shen CY. Logistic growth modelling of COVID-19 proliferation and its international implication. 2020. VOLUME 96, P582-589, JULY 01, 2020

DOI:https://doi.org/10.1016/j.ijid.2020.04.0

https://www.ijidonline.com/article/S1201-9712(20)30303-9/fulltext Accessed 19 June, 2020

21. Hu Z, Zhang J, Wang H, Ma W, Liao F. 2013. Dynamics analysis of a delayed viral infection model with logistic growth and immune impairment.2013. https://doi.org/10.1016/j.apm.2013.06.041 https://www.sciencedirect.com/science/article/pii/S0307904X13004435

22. Arenas AR, Thackar NB. The logistic growth model as an approximating model for viral load measurements of influenza A virus.2016. Mathematics and Computers in Simulation Volume 133, March 2017, Pages 206-222 https://www.sciencedirect.com/science/article/abs/pii/S0378475416301951

23. Gershenfeld NA. The Nature of Mathematical Modeling.1999. Cambridge, UK: Cambridge University Press. ISBN 978-0-521-57095-4. 
24. WHO. Coronavirus disease 2019 (COVID-19) Situation Report - 73.

https://www.who.int/docs/default-source/coronaviruse/situation-reports/20200402-sitrep-73-

covid- 19.pdf?sfvrsn=5ae25bc7_6\#: :text=The\%20incubation

\%20period\%20for\%20COVID, persons\%20can\%20be\%20contagious.

Accessed 28 June, 2020.

25. Ministry of Health, Malaysia. Malaysia will be declared free from Covid-19 if no new cases for 28 days, says Health DG. The Star. 11 June, 2020.

https://www.thestar.com.my/news/nation/2020/06/11/malaysia-will-be-declared-free-from-covid-

19-if-no-new-cases-for-28-days-says-health-dg

Accessed 28 June, 2020.

26. Malaysia's daily updates and press statement by the Ministry of Health, Malaysia

http://covid-19.moh.gov.my/terkini/012020/situasi-terkini-25-jan-2020

TO ...

http://covid-19.moh.gov.my/terkini/062020/situasi-terkini-17-jun-2020

Accessed daily from Jan. 25 -Jun. 17, 2020 . The website contains archived data.

27. Meyer PS. Bi-logistic growth.1994.

Technological Forecasting and Social Change 47: 89-102

28. Selamat A, Awang Y, Mohamed MTM ,Wahab Z, Osman M. Use of Absolute Function and Its Associates in Formation and Redevelopment of Mathematical Models in Some Plant Quantitative Physiology: Salinity Effects on Leaf Development of Schefflrea arboricola and Harvest Index in Rice. 2008. pp. 165-170, American Institute of Physics Conference Proceeding, Vol. 94.

29. Exponential decay. http://atlas.physics.arizona.edu/ shupe/Physics_Courses/

Phys_586_S2015_S2016_S2017/Readings MS/ExponentialDecay_Wiki.pdf

Accessed 15 June, 2020

30. SAS Institute. SAS version 9.4. 2014. SAS Institute Inc. Cary, NC.

31. CHAN D, YING TP. MCO phase 4 will help MOH.

New Straits Times, April 24, 2020

https://www.nst.com.my/news/nation/2020/04/587252/mco-phase-4-will-help-moh Accessed June 24, 2020

32. Malaysia: Weather Overview https://www.holidayweather.com/country/malaysia/\#: :text=The\%20humidity\%20in\%20Malaysia\%20is, in\%20November\%20in\%20Peninsular\%20Malaysia.

Accessed June 24, 2020 
33. Lin K, Fong DYT, Zhu B, Karlberg J. Environmental Factors on the SARS Epidemic: Air

Temperature, Passage of Time and Multiplicative Effect of Hospital Infection.2006.

Epidemiol Infect. 2006 Apr;134(2):223-30. doi: 10.1017/\$0950268805005054.

https://pubmed.ncbi.nlm.nih.gov/16490124/

Accessed 24 June, 2020

34. Chan K H, Malik Peiris JS., Lam SY. Poon L L M, Yuen KY, Seto WH.2011.

The Effects of Temperature and Relative Humidity on the Viability of the SARS Coronavirus

Volume 2011 |Article ID 734690 | 7 pages | https://doi.org/10.1155/2011/734690

https://www.hindawi.com/journals/av/2011/734690/

Accessed 20 June, 2020

35. Temperature has 'modest' effect on SARS-CoV-2 transmission rates. COVID-19: Latest news and resources. Medical on lines.

https://www.medicalnewstoday.com/articles/temperature-has-modest-effect-on-sars-cov-2Accessed 20 June, 2020.

36. Brassey J, Heneghan C, Mahtani KR, Aronson JK. Do weather conditions influence the transmission of Covid-19. 2020. The Oxford COVID-19 Evidence

Service Team, Centre for Evidence-Based Medicine, Nuffield Department of Primary Care Health Sciences, University of Oxford.

https://www.cebm.net/covid-19/do-weather-conditions-influence-the-transmission-of-thecoronavirus-sars-cov-2/

Accessed 22 June, 2020

37. Azil F. Pakar Kesihatan Taiwan beri amaran gelombang kedua COVID-19 hujung 2020.

Astro Awani | Diterbitkan pada Mei 09, 2020 21:43 +08 | Durasi: 1 minit, 56 saat

http://www.astroawani.com/berita-malaysia/pakar-kesihatan-taiwan-beri-amaran-gelombangkedua-covid-19-hujung-2020-242311

Accessed 22 June, 2020

38. Malaysia reports 80 percent of COVID-19 deaths had chronic ...

outbreaknewstoday.com > malaysia-reports-80-percent-..

http://outbreaknewstoday.com/malaysia-reports-80-percent-of-covid-19-deaths-had-chronicdiseases-45565/

Accessed 22 June, 2020

\section{Acknowledgement}

The authors would like to thank to the Ministry of Health, Malaysia and staffs for providing the daily updates and reports on the covid pandemic in Malaysia. 


\section{Funding}

No funding.

\section{Author information}

\section{Affiliation}

1. Analytic Unit, ASA Production (ASAPRO Resources), Bangi, Malaysia.

2. Faculty of Information Technology, INTI International University, Nilai, Malaysia.

\section{Contributions}

The draft is initially written by A. Selamat. The draft is then edited and corrected by DK Ahmad, MN Ahmad, and AS Ahmad for data analysis interpretation and graphic presentation. All authors have agreed to the final edited draft.

Corresponding author

DK Ahmad.

\section{Ethics declarations}

\section{Ethics approval and consent to participate}

Not applicable.

\section{Consent for publication}

Not applicable.

\section{Competing interests}

No competing interests as declared by the authors. 


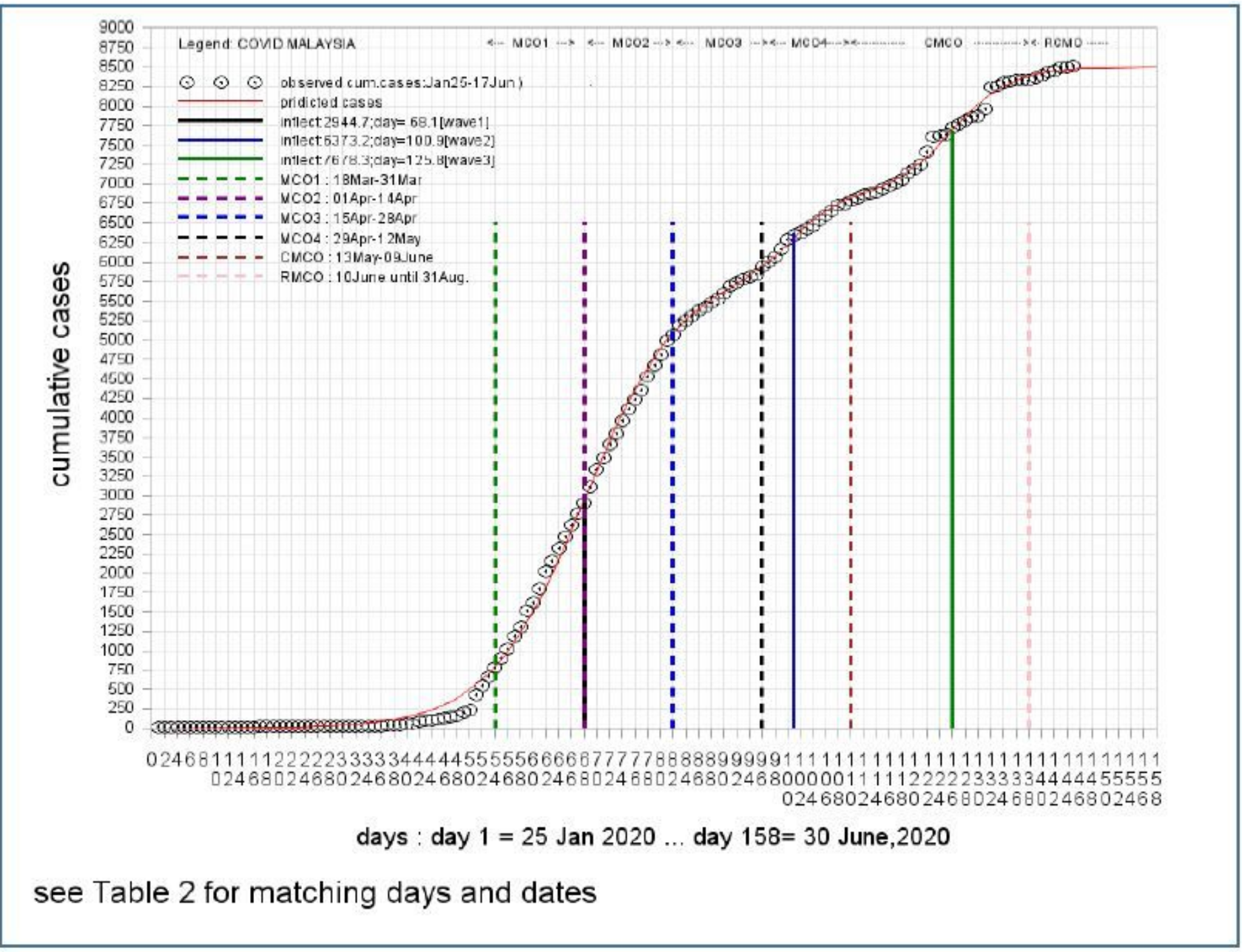

\section{Figure 1}

The observed and predicted of cumulative covid-19 cases over days in six movement control order (MCO) phases during the period of Jan. 25 - Jun. 17, 2020 and Jan. 25 - Jun. 30, 2020, respectively. The vertical solid lines are referenced to inflection points of the primary cycle (cycle 1), cycle 2 , and cycle 3 as indicated in the Figure. 


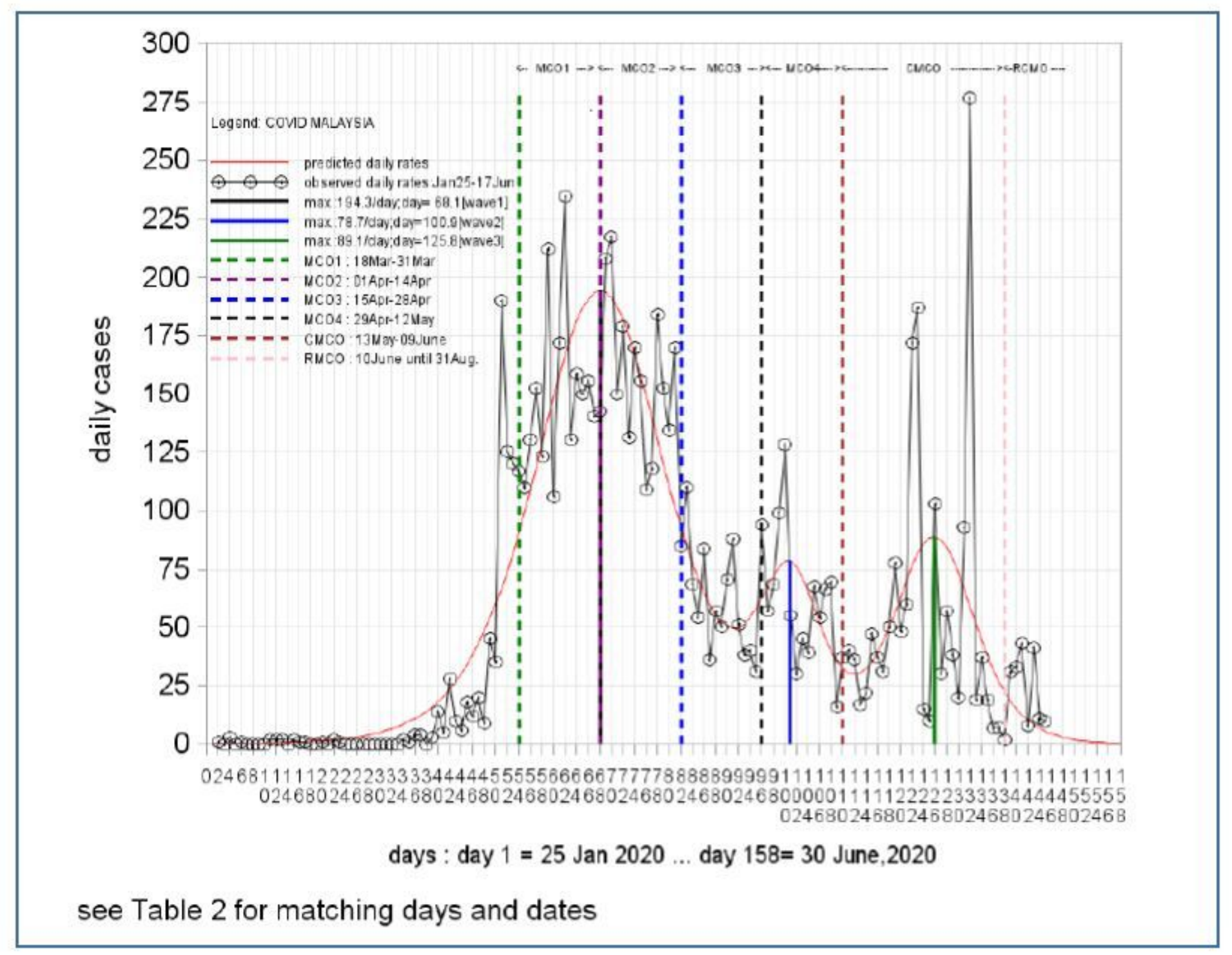

Figure 2

The observed and predicted daily covid-19 cases over days in six movement control order (MCO) phases during the period of Jan. 25 - Jun. 17, 2020 and Jan. 25 - Jun. 30, 2020, respectively. The vertical solid lines referenced to time of inflections that associated with the predicted daily maximum of the primary cycle (cycle 1 ), cycle 2 , and cycle 3. 


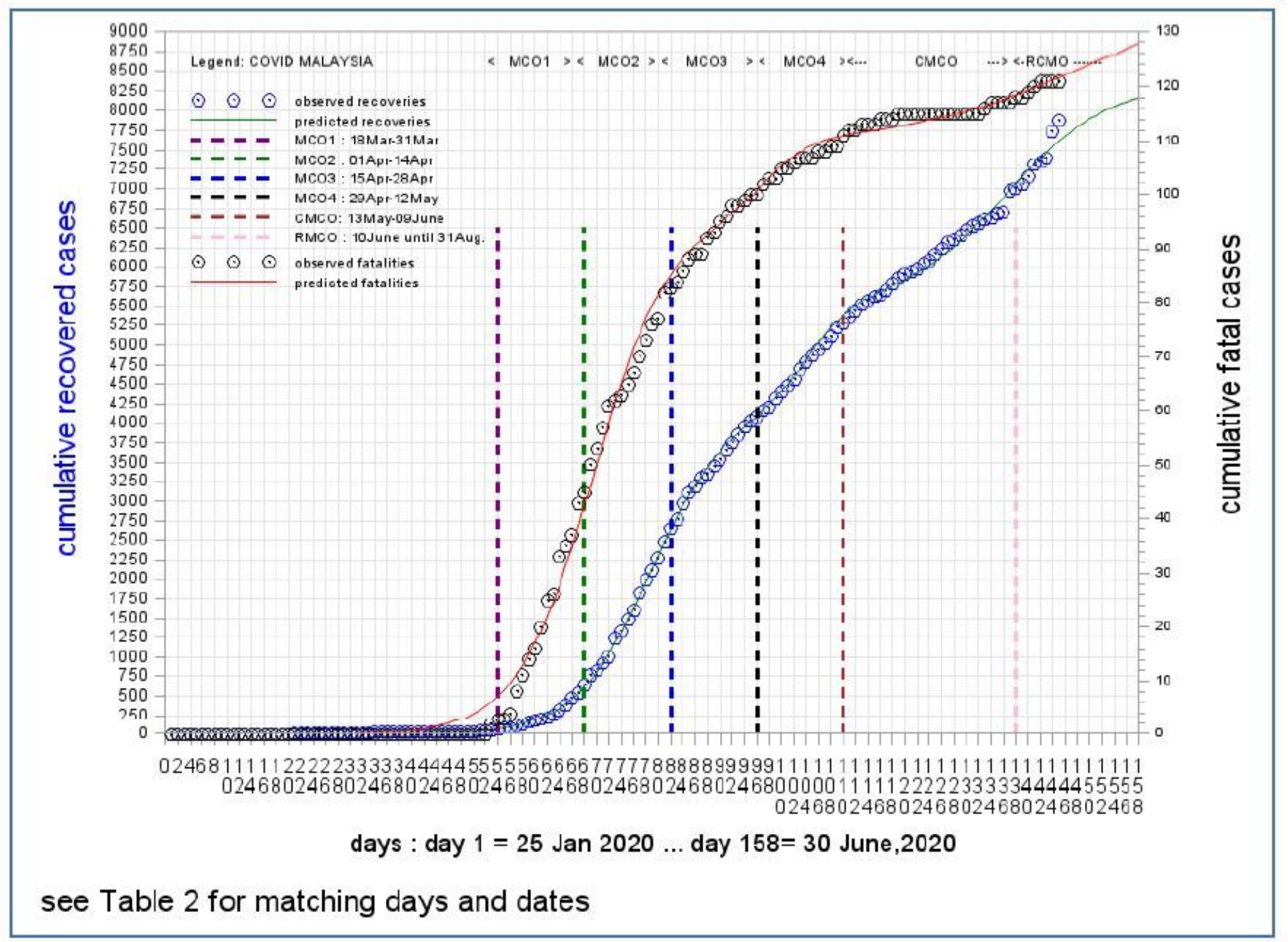

Figure 3

Observed (Jan. 25 - Jun. 17, 2020) and predicted (Jan. 25 - Jun. 30, 2020) cumulative recoveries and fatalities due to Covid-19 infestation in six MCO phases. 


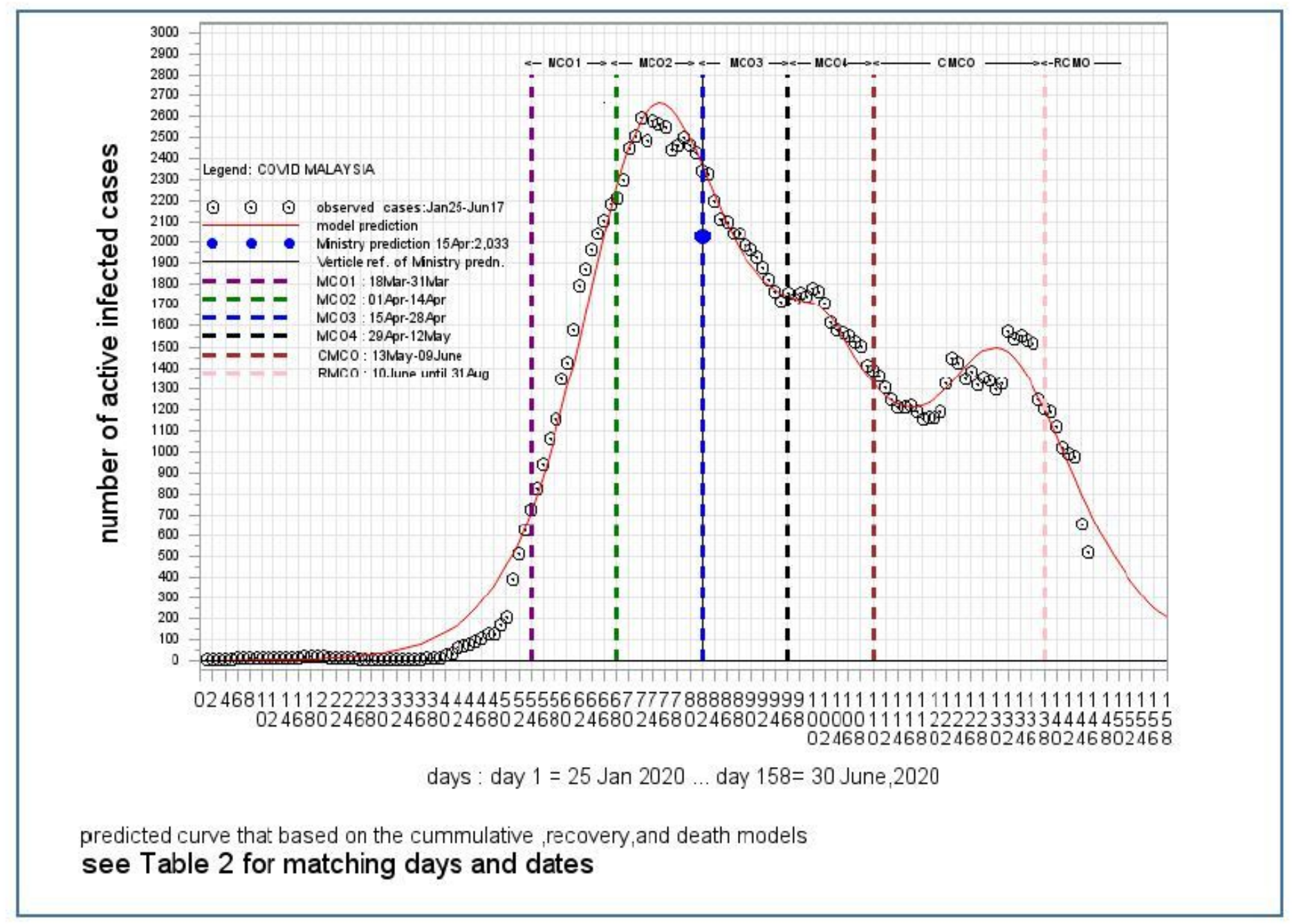

Figure 4

Observed (Jan. 25 - Jun. 17, 2020) and predicted (Jan. 25 - Jun. 30, 2020) cumulative active cases due to Covid-19 infestation in six MCO phases. 